\title{
Influence of anticyclonic eddies on the Biogeochemistry from the Oligotrophic to the Ultraoligotrophic Mediterranean (BOUM cruise)
}

\author{
T. Moutin ${ }^{1}$ and L. Prieur ${ }^{2}$ \\ ${ }^{1}$ Aix-Marseille Université, Université du Sud Toulon-Var, CNRS/INSU, UMR 6535, IRD, Mediterranean Institute of \\ Oceanography MIO, UM 110, 13288, Marseille, Cedex 09, France \\ ${ }^{2}$ Laboratoire d'Océanographie de Villefranche, CNRS/INSU UMR 7093, Université Pierre et Marie Curie, Observatoire \\ Océanologique de Villefranche, Villefranche sur mer, France
}

Correspondence to: T. Moutin (thierry.moutin@univ-amu.fr)

Received: 1 August 2011 - Published in Biogeosciences Discuss.: 10 August 2011

Revised: 20 July 2012 - Accepted: 10 August 2012 - Published: 8 October 2012

\begin{abstract}
We studied a longitudinal transect in the Mediterranean Sea (MS) and along this transect, the influence of anticyclonic eddies at three long duration (LD) stations. The deep chlorophyll maximum depth, the euphotic layer depth and the top of the nitracline depth are clearly correlated outside of the eddies, and deepen from the oligotrophic western to the ultraoligotrophic eastern MS. We provide evidence that the locations of the three LD stations studied were near the axis of the eddies. Their diameters were close to $100 \mathrm{~km}$ and the studied areas were less than $10 \mathrm{~km}$ from the centre of the eddies. The positions of the LD stations are marked by an increase in the flux function and a decrease in apparent oxygen utilization (AOU) and in excess density $(\sigma)$, as expected for anticyclonic eddies. Integrated mean primary production measured in situ inside the three studied eddies confirms the previous conclusion that integrated primary production (IPP) about $150 \mathrm{mgC} \mathrm{m}^{-2} \mathrm{~d}^{-1}$ may appear as a lower limit for IPP during strong oligotrophic conditions. The mesoscale activity is strong enough to locally modify the very welldocumented western-to-eastern gradient of trophic conditions in the MS. We proposed a new calculation for mixed layer depths (MLDs) enabling the determination of MLD to take into consideration processes occurring with time scales ranging from a few hours to several days, and also the winter MLD. Studying the main physical, chemical and dynamical characteristics of the three eddies enables us to consider that the vorticity barrier prevents any strong mixing and advection of outer water inside the eddy and explains why the depth range of eddies starts from the surface. As a first ap-
\end{abstract}

proximation, the anticyclonic eddies could be considered as closed systems dating back to the previous winter, making possible to draw first-order budgets. The daily new $\mathrm{N}$-input in the photic zone is virtually identical to the $\mathrm{N}$-export measured at $230 \mathrm{~m}$ by drifting traps. This means that the eddies are close to an equilibrium state where input is equal to loss. The annual $\mathrm{N}$-input by winter convection, which is a fundamental criterion for new nutrient availability, may be extremely variable inside eddies, with W-MLD varying from $90.5 \mathrm{~m}$ at the western station to $396.5 \mathrm{~m}$ at the eastern station. W-MLDs are always deeper inside the eddies than outside where they are in keeping with climatological averages. AOU was low inside the eddies; this together with the nearidentical export measured at 230 and $460 \mathrm{~m}$ seems to indicate that eddy cores are areas where low mineralisation of particulate organic matter occurs. "In" and "out" AOU comparisons indicate lower mineralisation inside the eddies suggesting a higher efficiency for $\mathrm{CO}_{2}$ sequestration via sedimentation of particulate organic matter. The three eddies are enriched in dissolved organic carbon (DOC). Sequestration of $\mathrm{CO}_{2}$ by vertical export of accumulated DOC therefore seems to be higher inside eddies. The relative importance of DOC transport in the biological pump is probably one of the main characteristics of low-P low chlorophyll (LPLC) areas, and it is likely to be reinforced inside anticyclonic eddies. The numerous anticyclonic eddies in the MS are likely to influence the water masses and their dispersion, and therefore have a strong impact on the biogeochemical properties at the scale of the MS. 


\section{Introduction}

The MS is a semi-enclosed sea with the general circulation resulting in a westward-eastward gradient of nutrient availability in the upper layer (McGill, 1961; Moutin and Raimbault, 2002) therefore producing a large range of trophic conditions. It is also a sea with intense mesoscale activity, as shown by the numerous "quasi"-permanent anticyclonic eddies encountered (Puillat et al., 2002, Taupier-Letage, 2008). Such physical structures are known to play a significant role in the biogeochemistry of the sea, although the integrated impact of these intermittent events is debated (Jenkins et al., 2008; Ledwell et al., 2008). It is therefore of great interest to study how such mesoscale structures may modify the welldocumented gradients in the Mediterranean Sea.

The oligotrophy in the western basin and the ultraoligotrophy in the eastern basin of the MS are principally the result of small loads and unusual anti-estuarine circulation, in which nutrients are net exported from the basins at the straits, namely of Gibraltar and of Sicily, respectively (Sarmiento et al., 1988; Stratford et al., 2000). A major role of the biological pump has been suggested for the long-term maintenance of these gradients (Crispi et al., 2001). The MS is also characterized by a high $\mathrm{N}: \mathrm{P}$ ratio in both the mineral and organic pools (Mc Gill, 1961, 1965; Coste et al., 1984; Raimbault and Coste, 1990; Moutin and Raimbault, 2002), which are higher in the eastern than in the western basin (Krom et al., 1991). Three fundamentally different processes have been proposed to explain the typical N:P ratios in the MS. Firstly, there is the biological process of nitrogen $\left(\mathrm{N}_{2}\right)$ fixation (Bethoux and Copin-Montegut, 1986; Bonin et al., 1989; Sachs and Repeta, 1999; Kerhervé et al., 2001; Pantoja et al., 2002) which may lead to nitrogen accumulation; however, recently acquired data indicate very low nitrogen fixation rates (Ibello et al., 2010; Yogev et al., 2011; Bonnet et al., 2011). Secondly, there is the chemical process of phosphate adsorption onto iron-rich particles which leads to further P-depletion in the Mediterranean Sea (Krom et al., 1991); however, it has been demonstrated that phosphate removal by adsorption from the water column does not represent a significant enough sink for phosphate in the MS to explain the high N:P ratios (Pan et al., 2002; Ridame et al., 2003). The third explanation is that high $\mathrm{N}: \mathrm{P}$ values are derived from the external nutrient inputs coupled with the very low denitrification rates linked with the oligotrophic status of the MS (Krom et al., 2010).

Fluxes of nutrients from depth are essential to sustain phytoplankton productivity in the euphotic zone of the oligotrophic ocean, yet the mechanisms regulating those fluxes remain enigmatic (Ledwell et al., 2008). It was recently demonstrated that mesoscale activities may provide ecological niches explaining the distribution of specific planktonic species (D'Ovidio et al., 2010) and that this scale should be taken into account in the global biogeochemical budget (Benitez-Nelson and McGuillicuddy, 2008; Lévy, 2008). Because of their relatively simple physical structure, anticy- clonic eddies have been well studied and their biogeochemical role has principally been considered to be that of water isolation giving rise to more oligotrophic conditions inside the eddies (Chapman and Nof, 1988; Krom et al., 1992). However, mode-water eddies (McGuillicuddy et al., 1999) tend to produce strong biological responses (McGuillicuddy et al., 2007) and appear to foster a shift in phytoplankton species composition in the Sargasso Sea (Sweeney et al., 2003). The Mediterranean Sea and the Sargasso Sea are typical oligotrophic areas where anticyclonic eddies may play an important role in vertical exchanges of nutrients and organic matter, and subsequently on the biological carbon pump.

The aim of this paper is to describe the water masses and general biogeochemical trends encountered in summer 2008 during the BOUM experiment in the MS, putting particular emphasis on the physical description of the anticyclonic eddies studied and their influence on biogeochemical trends, before concluding using first-order biogeochemical daily $\mathrm{N}-$ budgets.

The paper is organized as follows. After the introduction (Sect. 1), the material and method (Sect. 2) are limited to a presentation of the BOUM transect in the MS and specific physical methods, while most usual methods for physical and biogeochemical parameters are presented in the Supplement (SM, Part A). The results section (Sect. 3) presents the water masses encountered along the longitudinal transect and specifically inside eddies. The main changes in deep and Levantine water properties are particularly pointed out, as well as the anomalies found inside the eddies. The dynamical, physical and biogeochemical characteristics of the eddies are then described, as well as the very low variability of all parameters in their cores. Finally, a "close to equilibrium" first-order nitrogen budget is presented for each eddy. The discussion (Sect. 4) is focused on specific results in order to better characterize the influence of eddies on the physics and the biogeochemistry of the MS. The origins of the anomalies inside the eddies are discussed by using new information from the winter mixed layer depths (W-MLD, SM Part B) in the eddy cores. The conclusion (Sect. 5) establishes the main results on the physics and the biogeochemistry of the MS.

\section{Material and methods}

\subsection{Sampling strategy}

The BOUM cruise took place during summer 2008 (from 16 June to 20 July) in the Mediterranean Sea and consisted of a $3000 \mathrm{~km}$ transect from the Rhône river mouth (western Mediterranean) to the Eratosthenes Seamount (eastern Mediterranean). Along this transect, 27 "short duration" (SD) and 3 "long duration" (LD) stations located in the centre of anticyclonic eddies were sampled (Table 1). The sampling strategy and the general characteristics of each station are detailed in Moutin et al. (2012). The locations of stations 


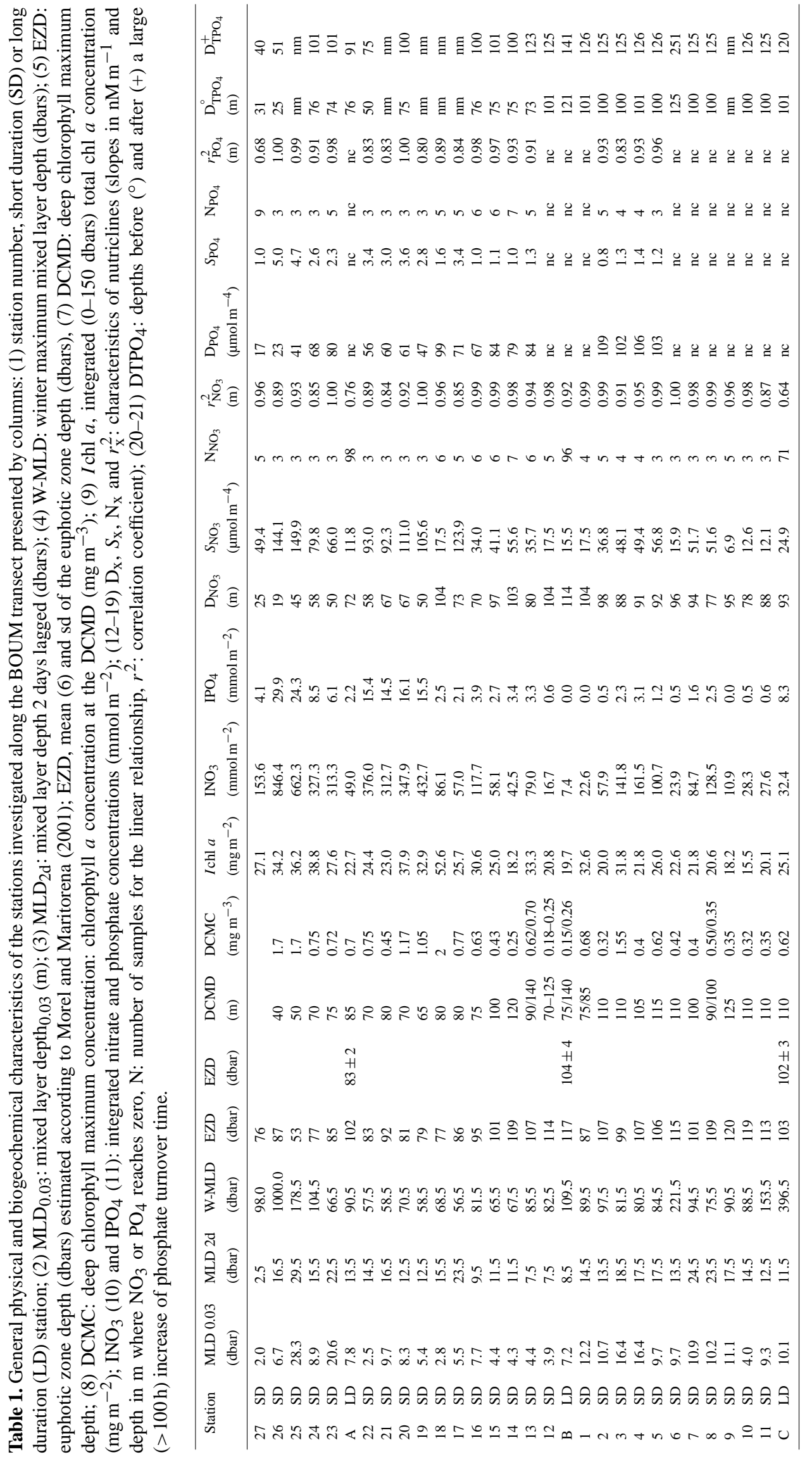



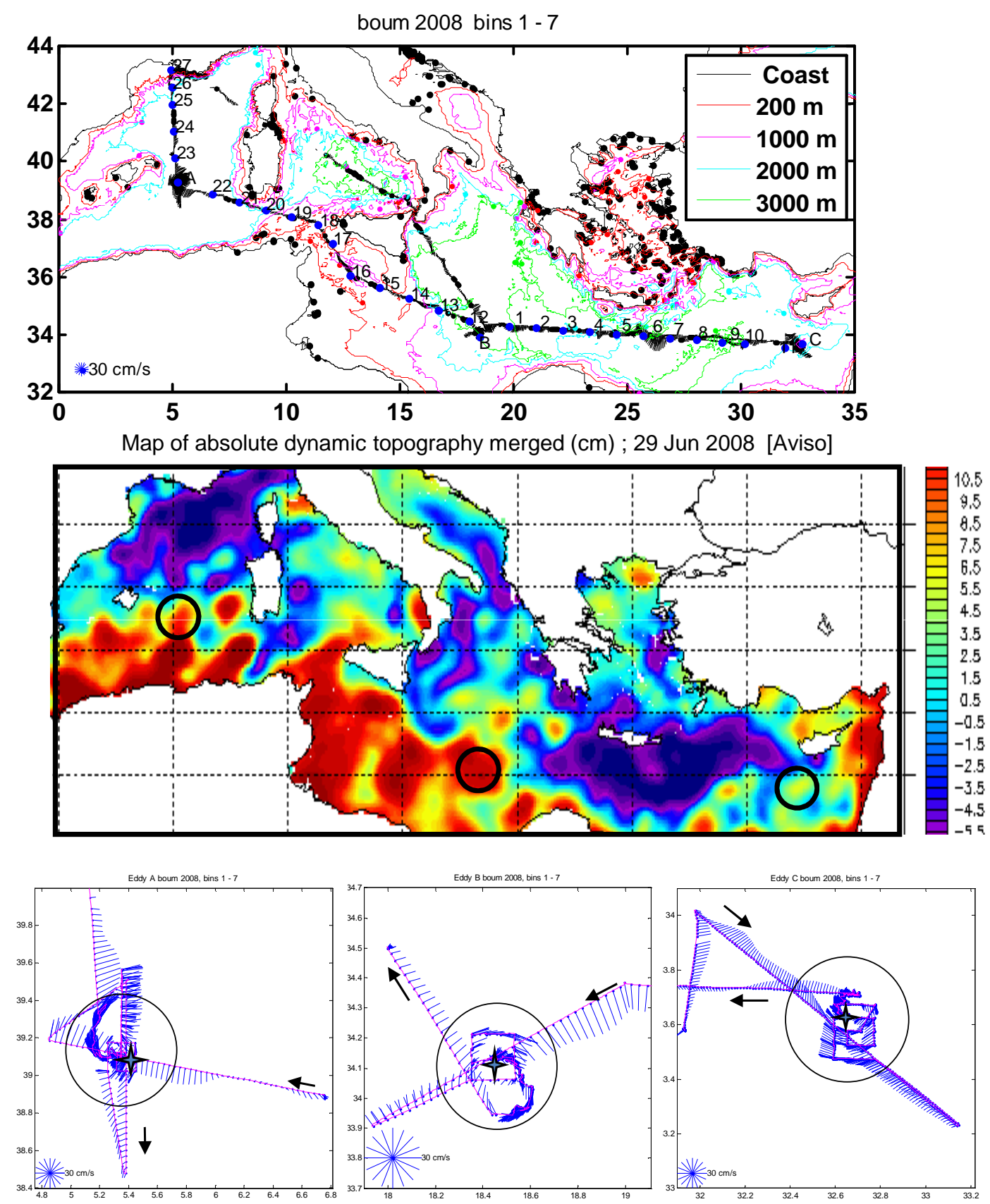

Fig. 1. Top: map of the bathymetry (GEBCO 1998) together with the mean velocities measured with the ship ADCP along the transect between 29 and $125 \mathrm{~m}$ depth (scale is indicated in blue in the lower left corner). The numbers along the transect correspond to the SD stations numbers indicated Table 1. Middle: map of the sea surface dynamic topography obtained from AVISO on 29th June 2008 and redrawn in Mercator coordinates (colour scale in $\mathrm{cm}$ ). Location of each eddy is indicated by a black circle around the local maximum. Bottom: details of ship course (pink) and mean ADCP currents measured around the three eddies, A, B, and C. Ship ADCP vectors are drawn each 10 min of cruise time from vessel location (velocity scales are indicated in the left corner of each map). The circles of diameters $\mathrm{rVaz}_{\mathrm{Max}}$ (Table 2) are positioned at the centre location of each eddy (shown by a blue star), as estimated before the beginning of LD stations.

along the transect are indicated in Fig. 1 (top) by number for SD stations or eddy name (A, B or C) for LD stations, together with bathymetry and ship mounted ADCP surface current data. The eastern part of the section (SD 1 to 11) was sampled first, then LD station $\mathrm{C}$ and $\mathrm{LD}$ station $\mathrm{B}$. The central section (SD 12 to 22) followed by LD station A was then sampled, and the cruise ended with the last five stations (SD 23 to 27). The black circles on the map of sea surface 
topography (Fig. 1 middle) contour the high levels induced by the three eddies (LD station A in the western MS, LD station $\mathrm{B}$ in the Ionian basin between the western and Levantine basins, and LD station $\mathrm{C}$ in the Levantine basin of the eastern MS). The well-known Ierapetra anticyclonic eddy (Fusco et al., 2003) located to the south-east of Crete island (near $34^{\circ} \mathrm{N}, 26^{\circ} \mathrm{E}$ ) was also traversed, (see ADCP currents, Fig. 1 top), but is weakly signed on absolute topography (Fig. 1 middle).

The detailed description of the usual methods for physical and chemical parameters measurements is presented in SM (Part A). All data and metadata are available at the following web address: http://www.obs-vlfr.fr/proof/php/x_datalist. php? xxop=boum\&xxcamp=boum.

\subsection{Specific physical characteristics}

Specific characteristics of the three studied eddies were calculated and are reported Table 2. It concerns (1) general properties obtained from direct observations, (2) anomalies determined from two "in" and "out" casts for each eddy, and (3) dynamical properties calculated from observations of a vessel-mounted ADCP (see SM including a comparison between the observations and the simulated eddy A).

\subsubsection{General characteristics}

The general characteristics of the eddies are reported Table 2 . $D_{\text {bottom }}$ is the bottom depth, and $D_{\text {range }}$ is the range of depth where eddy influence is marked on any or some properties; these depth ranges start at the surface as all eddies are strongly signed by circular-like surface currents and end at depth where anomalies are very weak. T20/850 dbars are baroclinic geostrophic transport at 20 dbars using a reference depth at 850 dbars and geopotential differences between "in" and "out" casts. For eddies A and B, this is only slightly less when using 1500 dbars. $\Delta X$ is the distance between the "in" cast and the "out" cast used as a reference to determine anomalies at constant depth while $\Delta H$ is the depth deepening of the maximum anomaly isopycnal $\sigma_{\text {MaxAno }}^{E}$ from "out" to "in" casts (see SM).

\subsubsection{Characteristics of the anomalies}

Anomaly is the difference at constant depth between "in" and "out" profiles for the selected parameter, with ${ }^{E}$ for eddy. $\mathrm{D}_{\text {TopAno }}^{E}$ is the depth of the top of anomaly, i.e. that anomaly weakens upwards. $\mathrm{D}_{\text {MaxAno }}^{E}$ is the depth where the absolute anomaly is maximum, and $\mathrm{D}_{\text {BotAno }}^{E}$ is the depth of the bottom of anomaly, i.e. that anomaly weakens downwards. The depths recorded here were taken with excess density $(\sigma)$, but some weak variations were observed for other parameters: $\sigma_{\text {MaxAno }}^{E}\left(\sigma\right.$ at $\left.\mathrm{D}_{\text {MaxAno }}^{E}\right), S_{\text {MaxAno }}^{E}$ (ibid for $S$ ), $\theta_{\text {MaxAno }}^{E}$ (ibid for $\theta$ ), $\mathrm{AOU}_{\text {MaxAno }}^{E}$ (ibid for $\mathrm{AOU}$ ), $\delta \sigma^{E}$ (anomaly in $\sigma$ observed at $\mathrm{D}_{\text {MaxAno }}^{E}$ ), $\delta S^{E}$ (ibid for $S$ ), $\delta \theta^{E}$ (ibid for $\theta$ ), $\delta \mathrm{AOU}^{E}$ (ibid for AOU). The depth-integrated anomalies for $\sigma, S, \theta$ and AOU between 0 and $850 \mathrm{dbars}$ are also reported in Table 2.

\subsubsection{Dynamical Characteristics}

$\delta G_{\text {Max }}$ is the maximum value of geopotential difference as observed between "in" and "out" profiles using a reference depth at $850 \mathrm{dbars}$, and $\mathrm{DG}_{\mathrm{Max}}$ is the depth of $\delta G_{\mathrm{Max}}$ and $\mathrm{Vaz}_{\text {Max }}$. VazMax is the azimuthal velocity maximum; by convention, the azimuthal velocity is negative in an anticyclonic eddy. Vaz Max $_{\text {in inferred from VMADCP, and rVaz }}$ ix is the distance of an eddy diameter between the $2 \mathrm{Vaz}_{\text {Max }}$. This distance should correspond to $L \sqrt{ } 2$ where $L$ is the Rayleigh distance (see SM). $\omega(\mathrm{Tr})$ rotation pulsation is always negative (number of days for one complete rotation). $f$ (lat) is the Coriolis parameter which is depending on latitude. $\zeta_{\min } / f$ is the ratio of the minimum relative vorticity occurring close to the eddy axis to the Coriolis parameter. This negative parameter, calculated as $2 \omega / f$, indicates the strength of the eddy which isolates the eddy core in solid rotation from outside advection (see also SM, Part C).

\subsubsection{Flux function}

The flux function is calculated for each cast by the integration of the geopotential anomaly referenced at 850 dbars. This function $F$ is very useful because the difference between 2 points, whatever their distance apart, is exactly equal to the baroclinic geostrophic transport with a sign directed positively and perpendicularly at the transect on the right. As an example, for eddy B (cast 115, $\mathrm{X}=1808 \mathrm{~km}), F=-28.437 \mathrm{~Sv}$; for the next cast along the transect (cast 2, $\mathrm{X}=1939 \mathrm{~km}$ ), $F=-31.880$; thus, $\delta F=$ $-28.437+31.880=3.443 \mathrm{~Sv}$, a value of transport reported for eddy B at line T20/850 in Table 2.

\subsection{Daily N-budget at the LD stations}

A first-order daily N-budget was carried out at the three LD stations. As a first approximation in this paper, we will consider that these eddies are in solid body rotation and are closed systems similar to giant mesocosms for biological and biogeochemical process studies. In this budget, we consider nitrogen input at the top and the bottom of the $0-150 \mathrm{~m}$ water column, the total primary production within the water column and particulate export at $230 \mathrm{~m}$.

The materials collected on the two PPS5 sediment traps deployed at 230 and $460 \mathrm{~m}$ depths over three days at each LD station were analyzed daily according to the methods detailed on the French national "traps" web site (http://www. obs-vlfr.fr/LOV/Pieges) for dry weight and specific C, N and $\mathrm{P}$ composition. Results are converted in $\mathrm{mg} \mathrm{m}^{-2} \mathrm{~d}^{-1}$ and the particulate $\mathrm{C}: \mathrm{N}: \mathrm{P}$ ratio calculated from the means obtained with the three 1-day values (Table 3 ). The standard deviation (sd) values are in italics under the corresponding means. 
Table 2. Specific depth characteristics of the three studied eddies at the three LD stations $\mathrm{A}(130 ; 186), \mathrm{B}(2.71)$ and $\mathrm{C}(17.71)$. Numbers in brackets correspond to CTD casts "in" (i.e. near eddy axis) and "out", respectively. As eddy B shows two pycnostads and an $S$ anomaly ( $S$ Ano) sign change, two parts, surface and deep, were distinguished. See Material and Methods for a detailed description of all specific characteristics.

\begin{tabular}{|c|c|c|c|c|c|}
\hline \multirow[t]{2}{*}{ Specific characteristics } & \multirow[b]{2}{*}{ Units } & \multicolumn{4}{|c|}{ LD Stations } \\
\hline & & $\mathrm{A}$ & $\mathrm{B}_{\text {surf }}$ & $\mathrm{B}_{\text {deep }}$ & $\mathrm{C}$ \\
\hline \multicolumn{6}{|l|}{ General } \\
\hline DBottom & dbars & 2758 & 3070 & 3070 & 923 \\
\hline $\mathrm{D}_{\text {range }}$ & dbars & $0-420$ & $0-250$ & $250-1200$ & $0-800$ \\
\hline T 20/850 dbars & $\mathrm{Sv}$ & 2.40 & $3.45(1.70)^{*}$ & $3.45(1.75)^{*}$ & 3.04 \\
\hline$\Delta X$ & $\mathrm{~km}$ & 142 & 128 & 128 & 71 \\
\hline$\Delta H$ & $\mathrm{~m}$ & 91 & 70 & 330 & 231 \\
\hline \multicolumn{6}{|l|}{ Anomalies } \\
\hline $\mathrm{D}_{\text {TopAno }}^{E}$ & dbars & 90 & 95 & 300 & 120 \\
\hline $\mathrm{D}_{\text {MaxAno }}^{E}$ & dbars & 160 & 135 & 600 & 380 \\
\hline $\mathrm{D}_{\text {BotAno }}^{E}$ & dbars & 420 & 250 & 1200 & 800 \\
\hline$\sigma_{\text {MaxAno }}^{E}$ & $\mathrm{~kg} \mathrm{~m}^{-3}$ & 28.202 & 28.433 & 29.012 & 28.84 \\
\hline$S_{\text {MaxAno }}^{E}$ & no dimension & 37.68 & 38.44 & 38.96 & 39.39 \\
\hline$\theta_{\mathrm{MaxAno}}^{\mathrm{E}}$ & ${ }^{\circ} \mathrm{C}$ & 14.27 & 15.86 & 15.06 & 17.2 \\
\hline $\mathrm{AOU}_{\text {MaxAno }}^{E}$ & $\mu \mathrm{mol} \mathrm{kg}{ }^{-1}$ & 13 & 5 & 21 & 12 \\
\hline$\delta \sigma^{E}$ & $\mathrm{~kg} \mathrm{~m}^{-3}$ & -0.66 & -0.32 & -0.134 & -0.251 \\
\hline$\delta S^{E}$ & PSU & -0.65 & -0.28 & +0.14 & +0.388 \\
\hline$\delta \theta^{E}$ & ${ }^{\circ} \mathrm{C}$ & 0.75 & 0.5 & 1.04 & 2.35 \\
\hline$\delta \mathrm{AOU}^{E}$ & $\mu \mathrm{mol} \mathrm{kg}-1$ & -50 & 0 & -30 & -40 \\
\hline Integrated $\sigma$ Ano $(0-850 \mathrm{~m})$ & $\mathrm{kg} \mathrm{m}^{-2}$ & -120 & - & -108 & -48.2 \\
\hline Integrated $S$ Ano $(0-850 \mathrm{~m})$ & $(\mathrm{psu}) \mathrm{m}^{-2}$ & -126.1 & - & 28.3 & 111.4 \\
\hline Integrated $\theta$ Ano $(0-850)$ & ${ }^{\circ} \mathrm{Cm}$ & 122 & & 555 & 580 \\
\hline $\begin{array}{l}\text { Integrated AOU Ano }(0-850 \mathrm{~m}) \\
\text { Dynamical Characteristics }\end{array}$ & $\mu \mathrm{mol} \mathrm{m}{ }^{-2}$ & -9328 & - & -9771 & -7665 \\
\hline$\delta \mathrm{G}_{\mathrm{Max}}$ & $\mathrm{m}^{2} S^{-2}$ & 1.26 & 0.42 & $0.98(0.58)$ & 0.65 \\
\hline $\mathrm{DG}_{\mathrm{Max}}$ & dbars & 40 & 30 & $30(250)$ & 90 \\
\hline VazMax $_{\text {Max }}$ & $\mathrm{ms}^{-1}$ & -0.33 & -0.20 & - & -0.20 \\
\hline $\mathrm{rVaz}_{\mathrm{Max}}$ & $\mathrm{km}$ & 58 & 42.5 & - & 48 \\
\hline$\omega(\mathrm{Tr})$ & $10^{-5} \mathrm{rad} / \mathrm{s}$ (days) & $-1.8181(4)$ & $-1.212(6)$ & - & $-1.3222(5.5)$ \\
\hline$f$ (lat) & $10^{-5} \mathrm{rad} / \mathrm{s}\left({ }^{\circ} \mathrm{N}\right)$ & $9.1531(39.1)$ & $8.1542(34.1)$ & $8.1542(34.1)$ & 8.0699 (33.7) \\
\hline$\zeta_{\min } / f$ & no dimension & -0.3973 & -0.2973 & - & -0.3277 \\
\hline $\mathrm{D}_{\mathrm{WML} 2008}^{E}$ & dbars & 90.5 & 109.5 & 109.5 & 396.5 \\
\hline DWML 2008 OUT & dbars & 57.5 & 89.5 & $300^{*}$ & 153.5 \\
\hline
\end{tabular}

All the pertinent information to calculate the daily $\mathrm{N}$ budget is presented in Table 4. The top nitracline $\left(\mathrm{D}_{\mathrm{NO}_{3}}\right)$ is reported directly from Table 1 , along with the slope of the nitracline $\left(\mathrm{S}_{\mathrm{NO}_{3}}\right)$. N-input by upward diffusion, from the bottom of the water column, is the product of the eddy diffusion coefficient $\left(K_{z}\right)$ measured at the level of the shallow nitracline (Cuypers et al., 2012) by the concentration gradient $S_{\mathrm{NO}_{3}}$. The overall averaged $K_{z}$ found in each eddy and within eddies between the pycnocline basis and $100 \mathrm{~m}$ depth is $\approx 10^{-5} \mathrm{~m}^{2} S^{-1}$ (i.e. $0.86 \mathrm{~m}^{2} \mathrm{~d}^{-1}$ ). This $K_{z}$ value, with an estimated error of about $40 \%$ (Table 2 in Cuypers et al., 2012), was considered constant. $\mathrm{N}$-input by $\mathrm{N}_{2}$ fixation is the mean integrated value measured in the photic zone, and atmospheric deposition is a mean value taken in the absence of rain (Bonnet et al., 2011 and further references herein, Table 1). The estimated errors could be 30-40\% (Bonnet et al., 2011, their Table 1). New N-input corresponds to the sum of these three $\mathrm{N}$-fluxes, because other possible inputs 
Table 3. Sediment trap data at the LD stations. Depth of collection, mean mass flux in $\mathrm{mg} \mathrm{m}^{-2} \mathrm{~d}^{-1}$ of matter (DW) and for each elements $\mathrm{C}, \mathrm{N}$ and $\mathrm{P}$ (sd in italics), mean C:N:P molar ratio.

\begin{tabular}{|c|c|c|c|c|c|c|}
\hline Station & $\begin{array}{l}\text { depth of collection } \\
\mathrm{m}\end{array}$ & $\begin{array}{c}\text { Mass flux } \\
\mathrm{mg} \mathrm{m}^{-2} \mathrm{~d}^{-1}\end{array}$ & $\begin{array}{c}\mathrm{PC} \\
\mathrm{mgC} \mathrm{m}^{-2} \mathrm{~d}^{-1}\end{array}$ & $\begin{array}{c}\mathrm{PN} \\
\mathrm{mgN} \mathrm{m}^{-2} \mathrm{~d}^{-1}\end{array}$ & $\begin{array}{c}\mathrm{PP} \\
\mathrm{mgP} \mathrm{m}^{-2} \mathrm{~d}^{-1}\end{array}$ & $\begin{array}{c}\mathrm{C}: \mathrm{N}: \mathrm{P} \text { molar ratio } \\
\text { 106:x:y }\end{array}$ \\
\hline \multirow{4}{*}{ LD A } & \multirow{2}{*}{230} & 14.26 & 2.52 & 0.35 & 0.16 & \multirow[t]{2}{*}{$106: 13: 2.6$} \\
\hline & & 1.29 & 0.19 & 0.12 & 0.23 & \\
\hline & \multirow{2}{*}{460} & 16.61 & 1.68 & 0.31 & 0.19 & \multirow[t]{2}{*}{$106: 17: 4.7$} \\
\hline & & 5.16 & 0.54 & 0.22 & 0.16 & \\
\hline \multirow{4}{*}{ LD B } & \multirow{2}{*}{230} & 26.26 & 2.54 & 0.45 & 0.06 & \multirow[t]{2}{*}{$106: 16: 1.0$} \\
\hline & & 15.48 & 0.99 & 0.20 & 0.03 & \\
\hline & \multirow{2}{*}{460} & 21.80 & 1.26 & 0.19 & 0.06 & \multirow[t]{2}{*}{$106: 14: 2.0$} \\
\hline & & 24.57 & 0.88 & 0.11 & $*$ & \\
\hline \multirow{4}{*}{ LD C } & \multirow{2}{*}{230} & 17.27 & 3.09 & 0.49 & 0.04 & \multirow[t]{2}{*}{$106: 14: 0.5$} \\
\hline & & 7.93 & 0.49 & 0.05 & 0.00 & \\
\hline & \multirow{2}{*}{460} & 19.40 & 2.26 & 0.49 & 0.02 & \multirow[t]{2}{*}{$106: 20: 0.4$} \\
\hline & & 12.03 & 1.29 & 0.31 & 0.02 & \\
\hline
\end{tabular}

* one extremely high value was discarded; no SD can be calculated.

Table 4. Daily N-budget at the three LD stations A, B, and C.

\begin{tabular}{|c|c|c|c|c|}
\hline \multirow{2}{*}{ Specific characteristics } & \multirow[b]{2}{*}{ Units } & \multicolumn{3}{|c|}{ LD Stations } \\
\hline & & A & B & $\mathrm{C}$ \\
\hline $\mathrm{D}_{\mathrm{NO}_{3}}$ & $\mathrm{~m}$ & 72 & 114 & 93 \\
\hline$S_{\mathrm{NO}_{3}}$ & $\mu \mathrm{mol} \mathrm{m}{ }^{-4}$ & 11.8 & 15.5 & 24.9 \\
\hline Input by diffusion & $\mu \mathrm{mol} \mathrm{m}{ }^{-2} \mathrm{~d}^{-1}$ & 10.1 & 13.3 & 21.4 \\
\hline Input by nitrogen fixation & $\mu \mathrm{mol} \mathrm{m}{ }^{-2} \mathrm{~d}^{-1}$ & 12.5 & 15.2 & 0.2 \\
\hline Input by atmospheric deposition & $\mu \mathrm{mol} \mathrm{m}{ }^{-2} \mathrm{~d}^{-1}$ & 25.0 & 18.5 & 18.5 \\
\hline Input of new nitrogen & $\mu \mathrm{mol} \mathrm{m}{ }^{-2} \mathrm{~d}^{-1}$ & 47.6 & 47.0 & 40.1 \\
\hline $\mathrm{N}$ export at $230 \mathrm{~m}$ & $\mu \mathrm{mol} \mathrm{m}{ }^{-2} \mathrm{~d}^{-1}$ & 25.3 & 32.0 & 34.8 \\
\hline Integrated gross $\mathrm{N}$-primary production & $\mu \mathrm{mol} \mathrm{m}{ }^{-2} \mathrm{~d}^{-1}$ & 3470 & 4130 & 3560 \\
\hline Export vs. total production & $\%$ & 0.9 & 0.8 & 1.0 \\
\hline Regenerated vs. total production & $\%$ & 98.6 & 98.9 & 98.9 \\
\hline
\end{tabular}

are neglected and also because the eddies are presumed to be horizontally closed systems once formed. The sum of errors is estimated to be $70 \%$ using the square root of the mean variance of the three $\mathrm{N}$-fluxes. $\mathrm{N}$-export corresponds to the mean value measured on drifting traps at $230 \mathrm{~m}$ during the occupation of each site (Table 3 ) with an estimated error in the range of $40 \%$. The integrated gross $\mathrm{N}$-primary production is determined by dividing the integrated gross $\mathrm{C}$-primary production (GPP) by 6.6 , the classical $\mathrm{C}: \mathrm{N}$ ratio of particulate organic matter. GPP corresponds to $1.72 * \mathrm{NPP}$, the net primary production (NPP) measured in situ using the ${ }^{14} \mathrm{C}$ method (Moutin et al., 1999) and reported as integrated (PPp) values in Christaki et al. (2011, their Table 4). The two integrated primary production rate determinations were averaged for each eddy. The percentage of export production is calculated by dividing the $\mathrm{N}$-export by the integrated gross $\mathrm{N}$-primary production rate (Table 4 ). The percentage of production attributed to nutrient regeneration in the photic zone (regenerated production) is estimated by 100 times the dif- ference: 1 - (input of new $\mathrm{N}$ divided by the integrated gross $\mathrm{N}$-primary production).

\section{Results}

\subsection{Water masses and general biogeochemical trends}

\subsubsection{Potential temperature $(\theta)$ - salinity $(S)$ diagrams, a powerful tool to see the progressive modification of LIW from its source}

The main Mediterranean water masses encountered along the summer 2008 BOUM cruise transect are identified in Fig. 2 using $\theta-S$ diagrams where the $30 \theta-S$ casts are superimposed (see legend to find the significance of the different lines). Surface temperature was close to $24^{\circ} \mathrm{C}$ at LD station $\mathrm{A}, 28^{\circ} \mathrm{C}$ in the Ionian basin and reached a maximum value of $27^{\circ} \mathrm{C}$ in the eastern MS. Three layers are usually considered in the MS: the surface, intermediate and deep layers. The 

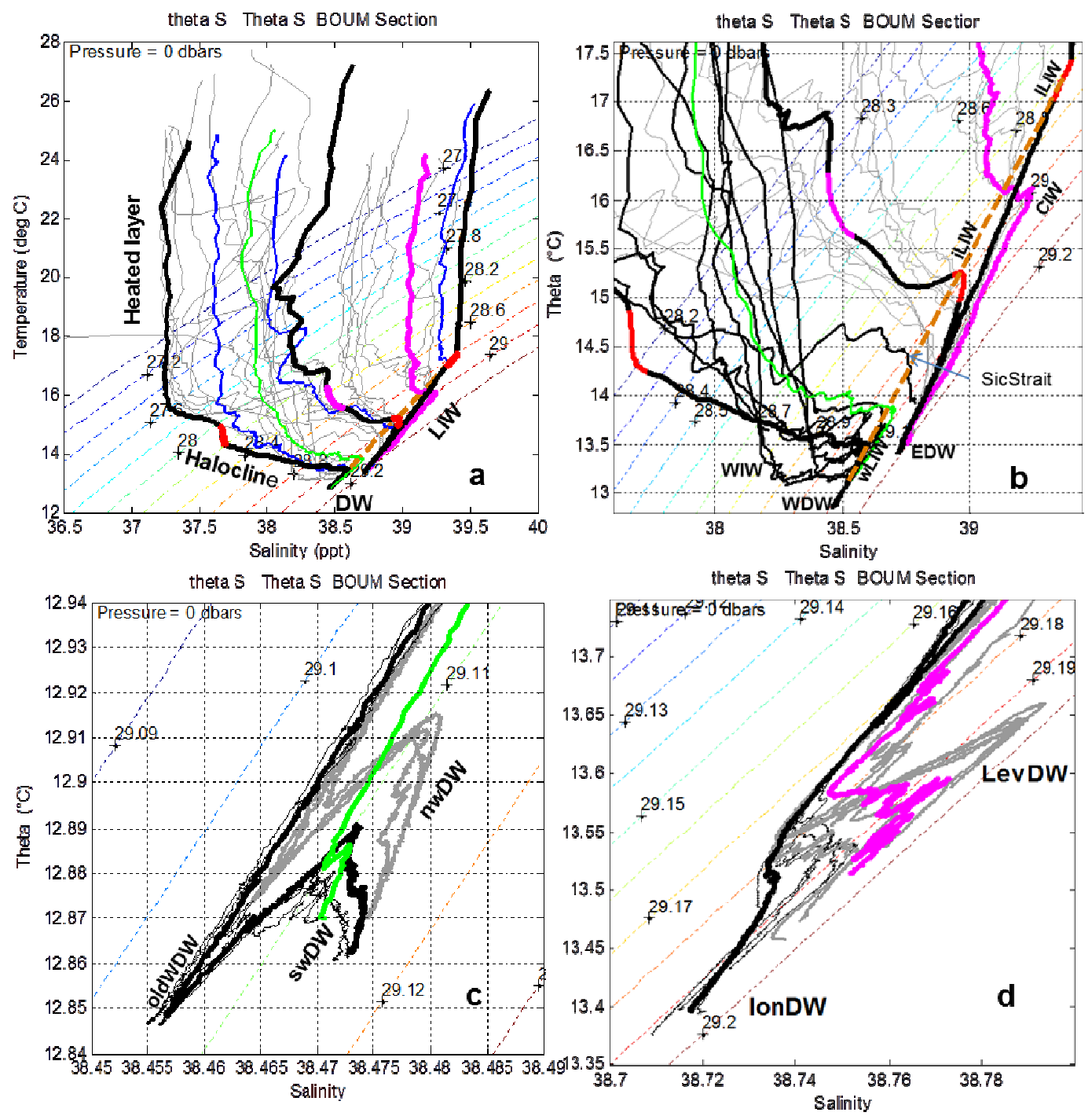

Fig. 2. $\theta-S$ diagrams for all the 30 deep casts of the BOUM section. (a) Full range, with indications of heated layer, halocline, LIW layer and deep layer, DW (see text). (b) Zoom in order to show intermediate waters using $\theta<17.4{ }^{\circ} \mathrm{C}$ and $S>37.5$. WIW: winter intermediate water in the western MS. ILIW, iLIW wLIW aligned along the dashed straight ochre line represent the Levantine, Ionian and western LIW, respectively. CIW: Cretan intermediate water. (c) Zoom for the western Mediterranean deep waters; oldWDW, swDW and nwDW stand for old western, southwestern and northwestern deep waters. All these deep waters were thought to have formed in northwestern MS, but the two latter after 2005-2006. (d) Deep layer in the eastern MS; LevDW was observed in the Levantine basin and IonDW in the Ionian basin. Lines: The thick black lines from left to right on panel (a) represent the LD stations A, B and C located at the centre of the eddies. The blue lines represent the closest SD stations investigated outside each eddy. The mauve thick line indicates the Ierapetra eddy (station 6), and the green thick line, the SD station located south of Sardinia (SD station 20). All other stations were drawn in thin grey in (a), in middle black for the western MS with SD station 18 (771 dbars deep) near the Sicilian sill identified as SicStrait in (b). The fine black and middle grey correspond to $\theta-S$ profiles in the south and northwestern MS in (c) and in the Ionian and Levantine basins on (d), respectively. The $\theta-S$ part at the depth ranges of the pycnostad found for each eddy A, B, C (see Table 1, $\mathrm{D}_{\text {TopAno }}^{E}$ to $\mathrm{D}_{\text {MaxAno }}^{E}$ ) is superimposed to thick black lines in thick red (panels (a) and (b)). For eddy B, the $\mathrm{B}_{\text {surf }}$ pycnostad was drawn in thick mauve.

surface layer, heated since the previous winter, is seen as an approximately vertical branch almost parallel to the $\theta$ axis. This layer corresponds roughly to the $0-70 \mathrm{~m}$ depth range and includes the summer mixed layer and the strong thermocline. Due to strong evaporation in the MS and the increased modification of Atlantic water entering at the Strait of Gibral-
$\operatorname{tar}\left(S=36.2\right.$ and $T=15.5^{\circ} \mathrm{C}$ for the $0-100 \mathrm{~m}$ depth range), $S$ varied between 37.2 at LD station A in the Algerian basin to 39.4-39.6 at LD station $\mathrm{C}$ in the Levantine basin, with values close to 38 in the northwestern MS. A regular increase in $S$ was observed from the western to the eastern part of the transect. 
The intermediate layer ( 70 to $700 \mathrm{dbars}, \theta<17.4^{\circ} \mathrm{C}$ ) is better represented in diagram $2 \mathrm{~b}$. A strong halocline was found in the western MS, $S$ increasing and $\theta$ decreasing with depth down to a first minimum of $\theta$ representative of the winter intermediate water formed in the northwestern MS, and below the well-known Levantine intermediate water (LIW) formed in the Levantine basin and identified with a maximum of $\theta$ and $S$ at depths of around 400 dbars. In the Ionian basin, the halocline is strongly attenuated and disappeared in the Levantine basin where the surface layer is connected directly to the LIW. The $\theta-S$ properties of LIW are changing along its flow from the Levantine basin (ILIW) toward the Ionian (iLIW) and the western basin (wLIW). The maxima of $\theta$ and $S$ strongly decrease westward, but they are approximately on the same straight line, shown in ochre (Fig. 2b).

The deep $\theta-S$ layer found at depths below 700 dbars shows similar patterns but for different values of $\theta$ and $S$ in the western and eastern basins (Fig. 2c and d for the western and eastern MS, respectively). A second minimum of $\theta$ was encountered at $1200-1500$ dbars in the western MS and at $1000 \mathrm{dbars}$ in the eastern MS. This minimum corresponds to the separation, along the isopycnals 29.106 and $29.180 \mathrm{~kg} \mathrm{~m}^{-3}$, between the old and new deep waters in each basin, respectively. In the western MS, the new deep water was thought to have formed during winter 2005-2006 in the northwestern MS. In the eastern MS, the new deep water was thought to have formed in winters of the early 1990s in the Aegean area (EMT period), which replaced the oldest deep water (Lascaratos et al., 1999; Malanotte-Rizzoli et al., 1999; CIESM 2009). However, the $2008 \theta-S$ diagram of the Ionian basin (Fig. 2d) did not exhibit a second minimum of $\theta$, which is interpreted as a recent deepest and densest water formation in the south Adriatic (see discussion), as before the EMT. The cast undertaken in the south of Sardinia is shown in green on Fig. 2a-c because it exhibits particular $\theta-S$ properties in deep water which are interpreted as the properties of the flow entering the Algerian basin from the Tyrrhenian basin.

Another type of intermediate water was also encountered along the BOUM section. The Cretan intermediate water (CIW), which is denser than the LIW, was encountered in the south of Crete and observed at the station inside the Ierapetra eddy (thick red). The three anticyclonic eddies (thick black lines on Fig. 2a-d), investigated during the BOUM experiment, show different $\theta-S$ properties in the different $\theta-S$ diagrams, but are not truly different or abnormal in comparison to the respective nearest station outside the eddies (thin blue lines on Fig. 2a).

In order to see the progressive modification of LIW from its source, the maximum $S$ value $\left(S_{\max }\right)$, the depth of $S_{\max }$ and $\mathrm{AOU}\left(S_{\max }\right)$ of each profile under the thermocline $(\theta<$ $17.4^{\circ} \mathrm{C}$ ) are shown on Fig. 3. The most salty water was then observed in eddy C with a $S_{\max }$ near 39.4 at a depth of $150 \mathrm{dbars}$, i.e. very close from the surface. Progressing westward, $S_{\max }$ decreases stepwise, firstly after the Ierapetra eddy, then after eddy B, then after the Strait of Sicily and ending near 38.6 in the western MS. $S_{\max }$ depths concomitantly increase from 150 dbars to 450 dbars, but peaked in each eddy. The LIW was encountered deeper inside than outside of each eddy. Another peak of $S_{\max }$ in depth was also observed near the Strait of Sicily $(X=1000 \mathrm{~km})$ but cannot be interpreted here.

\subsubsection{Main features of deep, intermediate and surface waters found on sections}

Full depth (0-3000 dbars) sections are presented in Fig. 4 and Fig. 5 from the Rhône river mouth in the western MS to the Eratosthenes Seamount in the eastern MS. The deeper waters in the western and the eastern basins are separated by the Strait of Sicily (x-axis at around $1100 \mathrm{~km}$ ). The black crosses on vertical sections indicate the CTD cast positions. The X-coordinates for LD stations A, B, C are approximately 450, 1750 and $3300 \mathrm{~km}$ from the station in the Rhône river mouth, respectively. LD station C, in the most eastern sector studied, was above the Eratosthenes Seamount at a depth of around $900 \mathrm{~m}$. Specific isopycnals $\left(\sigma_{\theta}\right)$ are drawn (Fig. 4) on each panel in thick white, 29.09 and 29.11, and 29.17 and $29.19 \mathrm{~kg} \mathrm{~m}^{-3}$ for the western and eastern basins, respectively, and each decreasing at a 0.5 interval from 29.1 in thin black lines. All stations were investigated from the surface to the bottom (Table 1), but two stations in the Ionian basin reached only 3020 dbars due to sensor limitation. The main features, $S, \theta$, dissolved oxygen concentration $\left(\mathrm{O}_{2}\right)$ and apparent utilization (AOU), are presented in Fig. 4. The deep minima in temperature and $S\left(\sigma_{\theta}\right.$ close to $29.18 \mathrm{~kg} \mathrm{~m}^{-3}$ ) which separate, in the more eastern part of the MS, the previous eastern Mediterranean deep water (pEMDW) from the transient eastern Mediterranean deep water (tEMDW) were observed during summer 2008 only in the Levantine basin at around $1000 \mathrm{~m}$ (Fig. 4). The tEMDW was still observed by a deep maximum in $S$ and in $\theta$ along the 29.19 isopycnal at around $2000 \mathrm{~m}$ depth. This water is also marked by a relatively lower $\mathrm{O}_{2}$ concentration and higher AOU compared to the deep waters of the Ionian basin. The deepest waters in the Ionian basin exhibited lower saline, colder temperatures (Fig. 2d), and higher $\mathrm{O}_{2}$ properties (Fig. 4 bottom) could be interpreted as typical of recent deep waters probably formed in the north Ionian or the Adriatic areas. In the western MS, the deep water density below 2000 dbars was close to 29.11 but sloped up northward in the area of deep water formation (northwestern MS, $\mathrm{X}<300 \mathrm{~km}$ ) where high $\mathrm{O}_{2}$ and low AOU were observed.

Above the deep waters, a minimum $\mathrm{O}_{2}$ layer (max AOU) was observed along the entire section. The depth of this layer, close to the 29.17 isopycnal, was as deep as $900 \mathrm{~m}$ near LD station $C$ and oscillated between 900 and $600 \mathrm{~m}$ through the eastern MS. The maximum AOU layer followed the 29.09 isopycnal and the $S_{\max }$ depth layer of the LIW in the western MS, but these two layers were clearly separated in the eastern MS where the $S_{\max }$ layer was shallower than the 29.17 


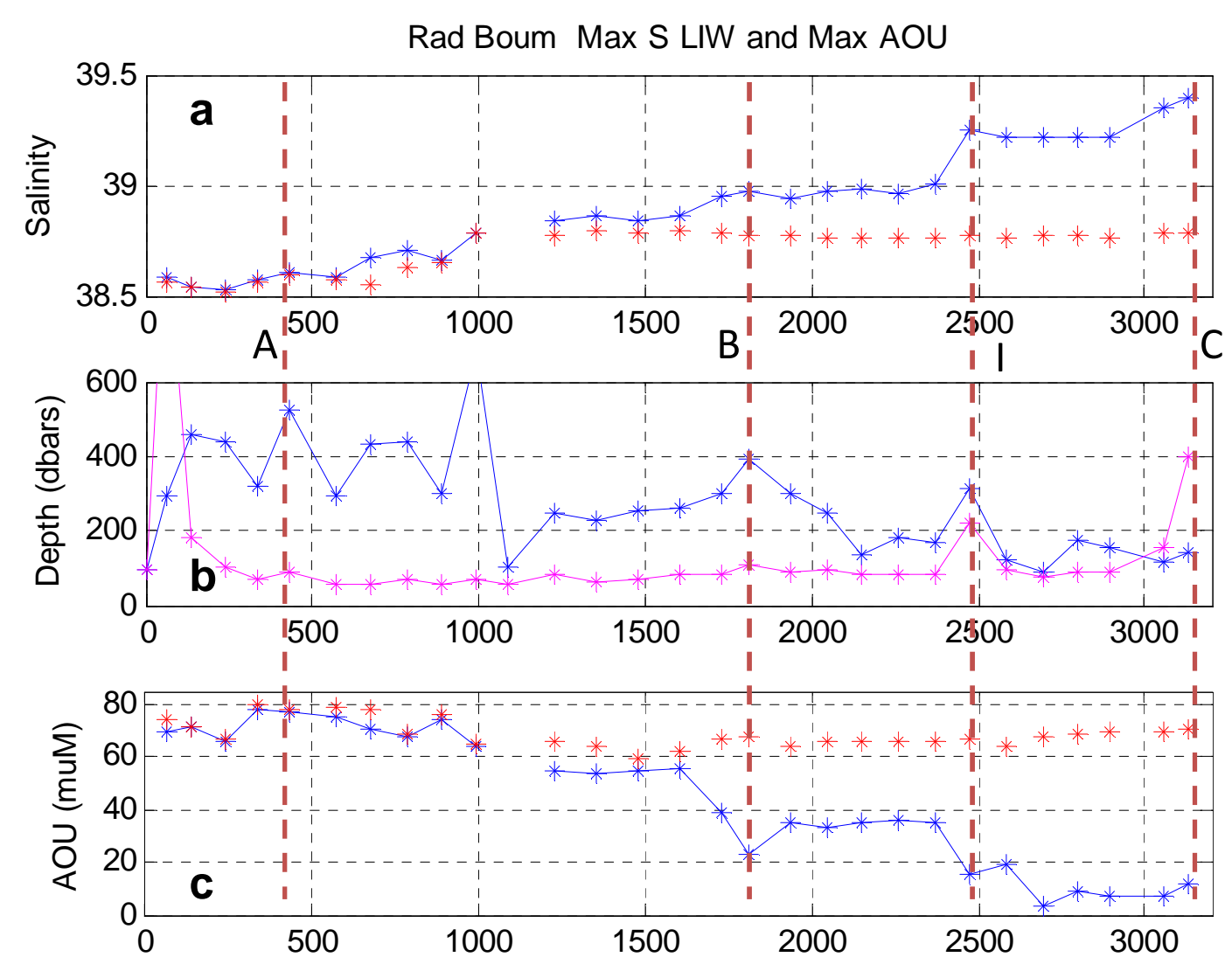

Fig. 3. Salinity (a), depth (b, dbars) and AOU $(\mathbf{c}, \mu \mathrm{M})$ values found on each vertical profile along the BOUM section at the maximum of $S$ (blue stars), and Salinity (a) and AOU (c) at the maximum of AOU (red stars). W-MLDs are indicated in mauve stars (b). The dashed vertical lines (red) show the locations of eddies A, B, Ierapetra and C, from left to right respectively. The x-axis is graduated in km of transect from the SD station 27 near the mouth of the Rhône river. In the (a) and (c) panels, the stations where bottom depths were $<150$ dbars were kept out.

isopycnal. This feature is shown on Fig. 3a and c by adding red crosses corresponding to $S$ and AOU values at the maximum of AOU. Maximum AOU decreases slightly $(70 \mu \mathrm{M}$ at LD station C to $60 \mu \mathrm{M}$ at LD station B) in the eastern MS but increases to $80 \mu \mathrm{M}$ in the western basin (LD station A). Figure $3 \mathrm{c}$ shows more precisely that $\mathrm{AOU}_{\mathrm{Max}}$ and $\mathrm{AOU}$ at $S_{\max }$ became close in the westernmost part of the eastern MS (X near $1600 \mathrm{~km}$ ) before the passage of LIW through the Strait of Sicily. Such a feature will be discussed in Sect. 4.

The anticyclonic eddies A, B and C are easily identified by local deepening of isotherms, isohalines and isopycnals (Fig. 4). At $X=2500 \mathrm{~km}$, the section crossed (SD 6) the Ierapetra anticyclonic eddy to the south of Crete. The deepenings are mainly visible in the first $400 \mathrm{~m}$, but they are still observed at deeper depths, down to $1500-2000 \mathrm{~m}$, indicating a probable deep influence of these physical structures. Anticyclonic eddies, Ierapetra included, are characterized by low AOU values $\left(<20 \mu \mathrm{mol} \mathrm{kg}^{-1}\right)$ close to the surface and even deeper down to $200 \mathrm{~m}$, particularly at LD station C (Fig. 4d). At LD station B, AOU was also low $\left(20 \mu \mathrm{mol} \mathrm{kg}^{-1}\right)$ near $500 \mathrm{~m}$, but was not as low as at LD station $\mathrm{C}\left(10 \mu \mathrm{mol} \mathrm{kg} \mathrm{kg}^{-1)}\right.$.
This indicates the presence of recent Levantine waters deep in eddy B. Deeper still and down to the bottom, AOU was close to $60 \mu \mathrm{mol} \mathrm{kg}{ }^{-1}$, a value higher than the $50 \mu \mathrm{mol} \mathrm{kg}-1$ AOU value characteristic of the recent deep waters surrounding eddy B in the Ionian basin. This feature could indicate that the new deep water does not penetrate under this eddy or that more organic particulate matter was remineralised there. In any case, eddy B has an influence on the whole water column. Eddy A did not have a deep, strong signature for $S$ and AOU.

Mineral nutrient concentrations, $\mathrm{NO}_{3}$ and $\mathrm{PO}_{4}$ (Fig. 5 top and middle), are close to zero in the upper surface layer (dark blue on the panels) and decrease at depth from west to east in accordance with classical trends in the MS (see Pujo-Pay et al. (2011) for a detailed description). The two colour scales for nitrate and phosphate concentration were chosen in accordance with the Redfield ratio (Rr) N/P = 16 (Redfield et al., 1963). Because the colours are not identical for nitrate and phosphate, the strong depletion in $\mathrm{P}$ vs. $\mathrm{N}$ in the whole MS, which is even higher in the eastern part, can be seen clearly. The bottoms of the nil concentration layers, corresponding 


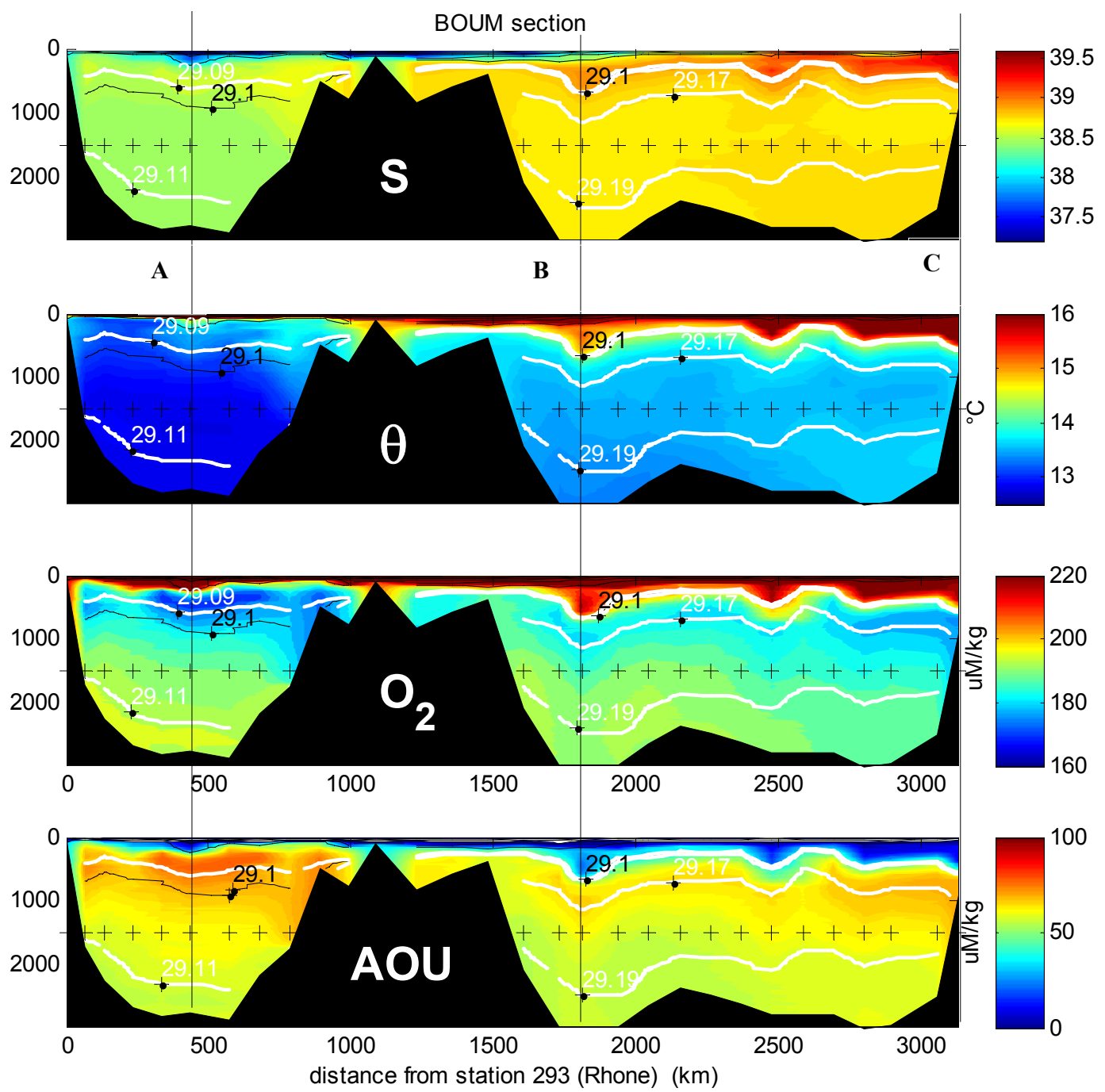

Fig. 4. Salinity ( $S$, PSU), potential temperature $\left(\theta,{ }^{\circ} \mathrm{C}\right)$, dissolved oxygen concentration and apparent oxygen utilization $\left(\mathrm{O}_{2}\right.$ and $\mathrm{AOU}$, $\mu \mathrm{mol} \mathrm{kg}{ }^{-1}$ ) sections along the BOUM transect (0-3000 dbars) from the Rhône river mouth in the western part of the MS to the Eratosthenes Seamount in the eastern part. Black vertical lines indicate the location of the three LD stations A, B, and C. Specific isopycnals $\left(\sigma_{\theta}\right)$ are superimposed in thick white on each panels, 29.09, 29.11, 29.17, and $29.19 \mathrm{~kg} \mathrm{~m}^{-3}$ for the western and eastern basins, respectively, and each decreasing at a 0.5 interval from 29.1 in thin black lines visible only by zooming.

to $\mathrm{D}_{\mathrm{NO}_{3}}$ and $\mathrm{DPO}_{4}$ (Table 1), have depths increasing from the west to the east, in accordance with classical trends from oligotrophy in the western towards ultraoligotrophy in the eastern basin of the MS. $\mathrm{D}_{\mathrm{NO}_{3}}$ may be considered as the best criterion for defining oligotrophy. $\mathrm{D}_{\mathrm{NO}_{3}}$ decreases from around $50-70 \mathrm{~m}$ in the western basin with lower values close to $20 \mathrm{~m}$ near the mouth of the Rhône river, to around 80$100 \mathrm{~m}$ in the eastern basin with a deeper value of $114 \mathrm{~m}$ at LD station B (Table 1). Only weak differences in the top nitracline and phosphacline depths were found when considering changes in phosphate turnover times (Table 1) instead of concentrations, when the latter were extremely low values (below $50 \mathrm{nM}$ ) measured in the upper waters of the eastern MS. Deep concentrations of $\mathrm{NO}_{3}$ and $\mathrm{PO}_{4}$ at 2000-
$3000 \mathrm{dbars}$ were circa 9 and $0.38 \mu \mathrm{M}$ in the western MS and 5 and $0.17 \mu \mathrm{M}$ in the eastern MS, respectively. Nitrate and phosphate maxima concentrations occurred within the intermediate layer between 500 and $1000 \mathrm{~m}$ depth, with values of $10.5 \mu \mathrm{M}$ and $0.42 \mu \mathrm{M}$, and $6.5 \mu \mathrm{M}$ and $0.22 \mu \mathrm{M}$, for nitrate and phosphate, in the western and eastern MS, respectively. These maxima are closely related and correspond to the maximum AOU. Mean integrated nitrate concentration was $382 \mathrm{mmol} \mathrm{m}^{-2}(\mathrm{sd}=229)$ in the western basin (stations 19 to 27$)$, and $63 \mathrm{mmol} \mathrm{m}^{-2}(\mathrm{sd}=49)$ in the eastern basin (stations 1 to 16). The linear regression $\mathrm{INO}_{3}=26.75 * \mathrm{IPO}_{4}$ $\left(r^{2}=0.90, \mathrm{~N}=30\right)$ indicates the strong relationship between these two nutrients and a similar decreasing pattern from the west to the east. The three eddies studied, A, B, C, as well 


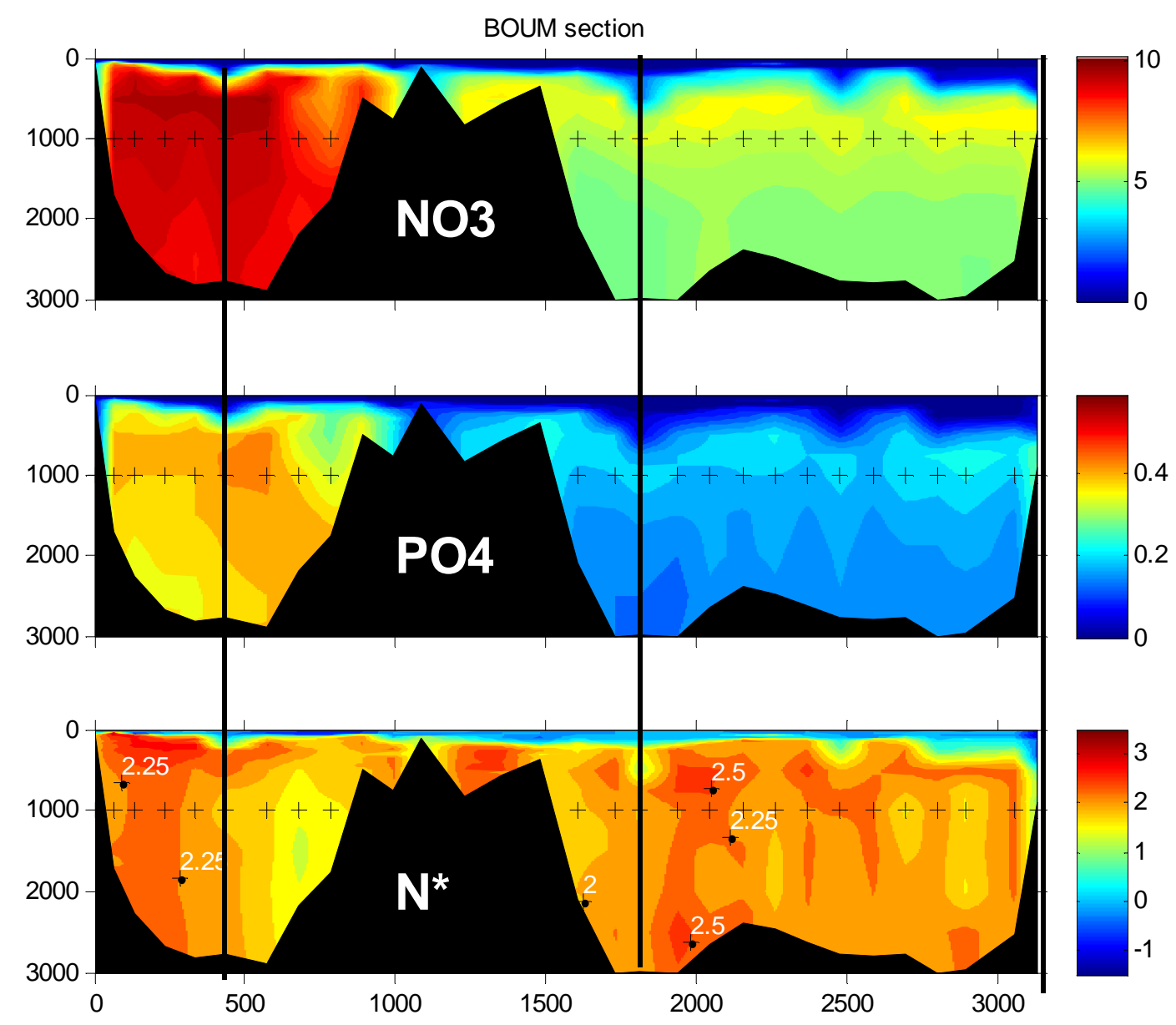

Fig. 5. Nitrate and phosphate concentrations $(\mu \mathrm{M})$ and $\mathrm{N}^{*}(\mu \mathrm{M})$ sections along the BOUM transect $(0-3000 \mathrm{dbars})$. $\mathrm{N}^{*}=\mathrm{NO}_{3}-\mathrm{PO}_{4} * \mathrm{Rr}$; $\mathrm{Rr}=17.7$ following Pujo-Pay et al. (2011). Linear interpolation between bottle data each 10 dbars was used to generate the distribution maps. Colour intervals were $0.25 \mu \mathrm{M}$ for $\mathrm{NO}_{3}$ and $\mathrm{N}^{*}$ and $0.025 \mu \mathrm{M}$ for $\mathrm{PO}_{4}$. Black vertical lines indicate the location of the three $\mathrm{LD}$ stations $\mathrm{A}$, $\mathrm{B}$, and $\mathrm{C}$. The $\mathrm{x}$-axis is graduated in $\mathrm{km}$ from SD 27 near the mouth of the Rhône river.

as the other eddies crossed during the transect, are also visible in nutrient concentrations by the local deepening of isopleths mainly in the $1000 \mathrm{~m}$ depth layer. The variable $\mathrm{N}^{*}$ was calculated as $\mathrm{N}^{*}=\mathrm{NO}_{3}-17.7 * \mathrm{PO}_{4}$ and plotted in Fig. 5 . The 17.7 factor is the $\Delta \mathrm{NO}_{3}: \Delta \mathrm{PO}_{4}$ ratio of particulate organic matter remineralisation below a depth corresponding to $\mathrm{O}_{2}=195 \mu \mathrm{mol} \mathrm{kg}{ }^{-1}$ (i.e. around 200-250 m) in deep and intermediate waters of the MS (see Pujo-Pay et al., 2011). $\mathrm{N}^{*}$ values were close to zero in surface waters reaching negative values, but, because $\mathrm{PO}_{4}$ measurements are very close to the detection limit in surface waters, these results should be taken with caution. Positive $N^{*}$ values were measured in deep waters confirming the P-deficiency of Mediterranean waters. Positive $\mathrm{N}^{*}$ values of $2.11 \mu \mathrm{M}(\mathrm{sd}=0.25 \mu \mathrm{M})$ were surprisingly observed both in the eastern and the western deep Mediterranean waters for depths $>200$ dbars, indicating that the relative variations of nitrate and phosphate concentrations in deep waters occurred in a proportion that con- serves $\mathrm{N}^{*}$, i.e. with a constant and low variable $\Delta \mathrm{NO}_{3}: \Delta \mathrm{PO}_{4}$ ratio. This feature will be discussed in Sect. 4 .

Figure 6 (bottom) illustrates the deepening of the deep chlorophyll maximum (DCMD, Table I) from $50-75 \mathrm{~m}$ in the west to $110-120 \mathrm{~m}$ in the east. The maximum chl $a$ concentration (DCMC) did not decrease regularly, despite the highest value of $1.7 \mathrm{mg} \mathrm{m}^{-3}$ being observed in the northwestern MS. The lowest value was measured at SD station 14 in the Ionian basin $\left(0.2 \mathrm{mg} \mathrm{m}^{-3}, \mathrm{X}=1500 \mathrm{~km}\right)$. A lower value of $0.15 \mathrm{mg} \mathrm{m}^{-3}$ was observed at LD station B in the centre of the Ionian basin at $75 \mathrm{~m}$, but with a secondary maximum of $0.26 \mathrm{mg} \mathrm{m}^{-3}$ also observed deeper at $140 \mathrm{~m}$. Two distinct peaks separated by at least $30 \mathrm{~m}$ depth were also observed in the two closest SD stations. After omission of the stations in the Sicilian channel, integrated chl $a$ varied between $38.8 \mathrm{mg} \mathrm{m}^{-2}$ in the western basin and $15.5 \mathrm{mg} \mathrm{m}^{-2}$ at SD station 10 in the eastern basin. An integrated chl $a$ value as low as $22.7 \mathrm{mg} \mathrm{m}^{-2}$ was measured in the western basin while a value as high as $32.6 \mathrm{mg} \mathrm{m}^{-2}$ was measured in the eastern 


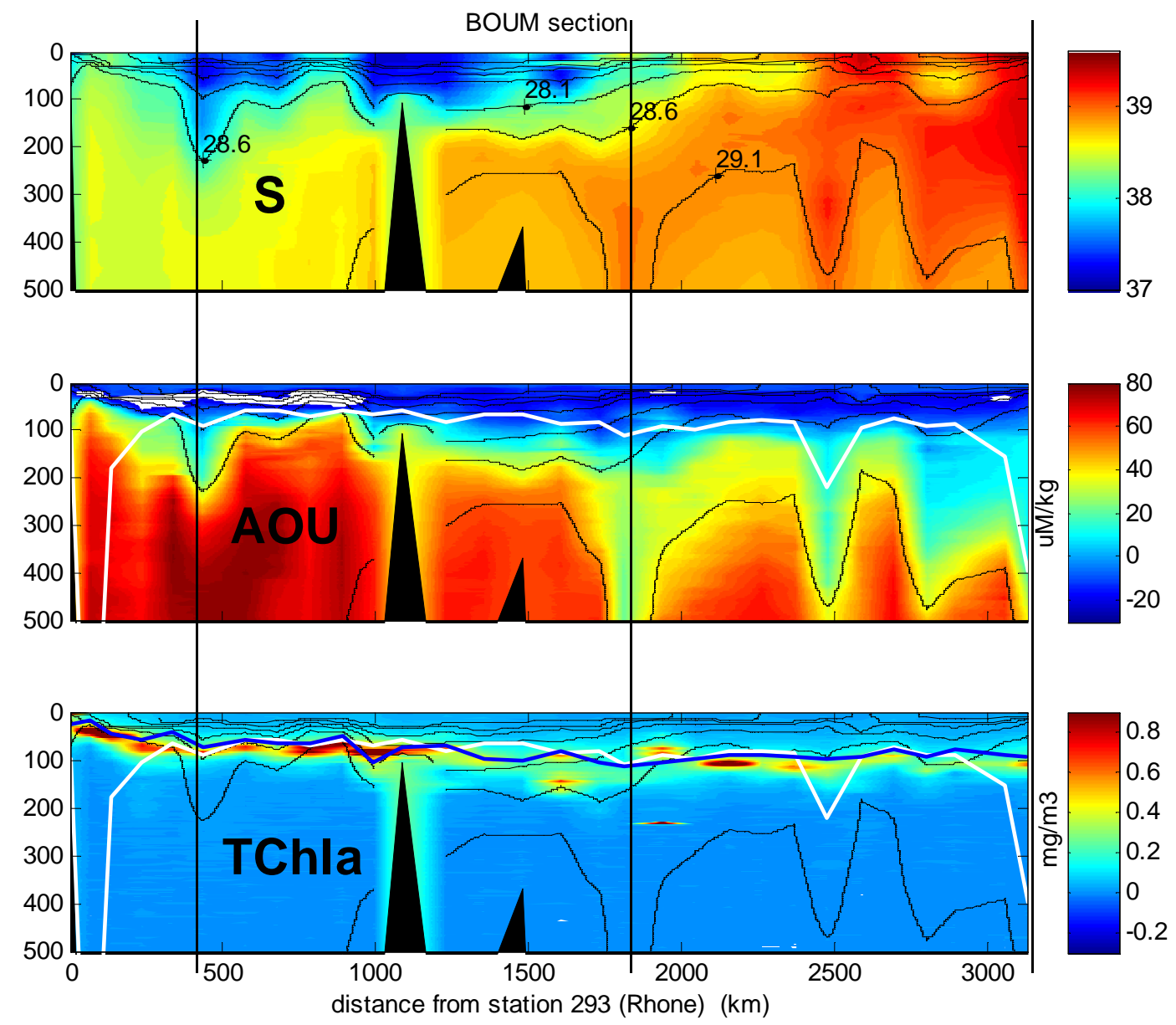

Fig. 6. Salinity, AOU ( $\mu \mathrm{mol} \mathrm{kg}{ }^{-1}$ ) and "Chlorophyll" section (in situ fluorescence units) along the BOUM transect (0-500 dbars). W-MLD and the top nitracline $\left(\mathrm{D}_{\mathrm{NO}_{3}}\right)$ are superimposed in white and blue lines on Fig. 6c, respectively. Isopycnals each $0.5 \mathrm{~kg} \mathrm{~m}{ }^{-3}$ under 29.1 are drawn in thin black lines.

sector. This value remains somewhat constant, as already observed by Moutin and Raimbault (2002). The deepening of DCMD and decreasing in DCMC is classically associated with the increasing trend in oligotrophy, as shown by the deepening of $\mathrm{D}_{\mathrm{NO}_{3}}$ drawn in thick blue line (Fig. 6 bottom). The euphotic zone depth (EZD) estimated from the discrete measurements of chl $a$ varied between 53 and $120 \mathrm{~m}$ (Table 1), with the deeper depths being obtained in the eastern MS in accordance with the eastwardly increasing oligotrophy. It is not possible to exhaust the nitrate deeper than the EZD, because it is directly linked to photosynthesis. Thus, the DCMD, the EZD and $\mathrm{D}_{\text {chlorophyll } a}$ are clearly correlated, and deepen from the west to the east of the MS. This is neither the case in the NW MS nor inside the eddies, the results of which will be discussed in Sect. 4.

The finest scale of depth ( $0-500$ dbars $)$ in Fig. 6 compared to Fig. 4 clearly shows the surface layer strongly influenced by low salinity waters $(S<38)$ originating from the Atlantic Ocean between $X=300$ and $X=1400 \mathrm{~km}$. LIW, shown by the already described deepening of salty water from the east to the west, is also better visible. LIW, represented by a maximum of $S$, is located close to 150 dbars from the eastern Levantine basin to the Ionian basin where it deepens to 300400 dbars before reaching the Sicilian channel. The surface $S$ was maximum and as high as 39.65 in eddy $\mathrm{C}$ at the eastern end of the section. The eddies are clearly marked by a deepening of the isohalines and particularly by the deepening of the 29.1 isopycnal in the eastern MS and 28.6 in the western MS (Fig. 4 and Fig. 6). These two latter isopycnals were also drawn for the AOU and $T \mathrm{chl} a$ sections (Fig. 6 middle and bottom). A strong deepening of AOU and isopycnals at Ierapetra eddy location $(X \approx 2450 \mathrm{~km})$ and near $2800 \mathrm{~km}$, which might be the Mersa-Matruh eddy (Robinson et al., 1991), were observed.

$\mathrm{MLD}_{2 \mathrm{~d}}$ (Table 1), representative of summer MLD, varied between 7.5 and $29.5 \mathrm{~m}$ during the BOUM cruise, after the omission of the very coastal SD station 27. AOU (Fig. 6 middle) is slightly negative in the mixed layer which corresponds to a slight $\mathrm{O}_{2}$ oversaturation of $6-10 \mu \mathrm{mol} \mathrm{kg}{ }^{-1}$, as is classically observed in upper marine waters. AOU reaches 


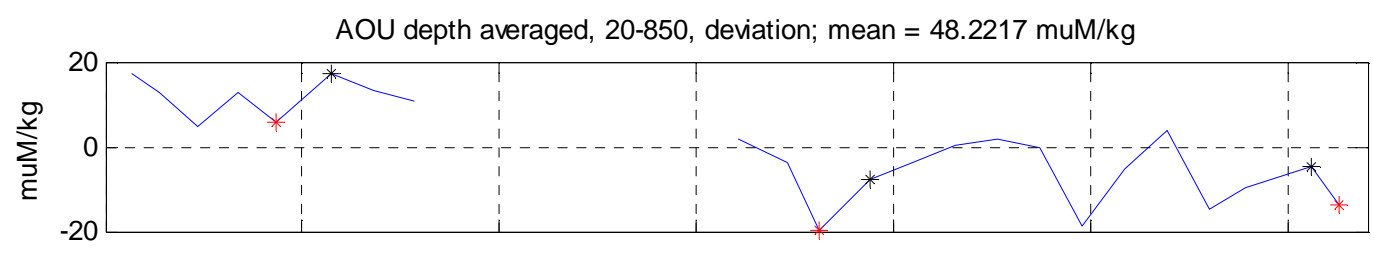

SAL depth averaged, 20-850, deviation; mean $=38.7748$

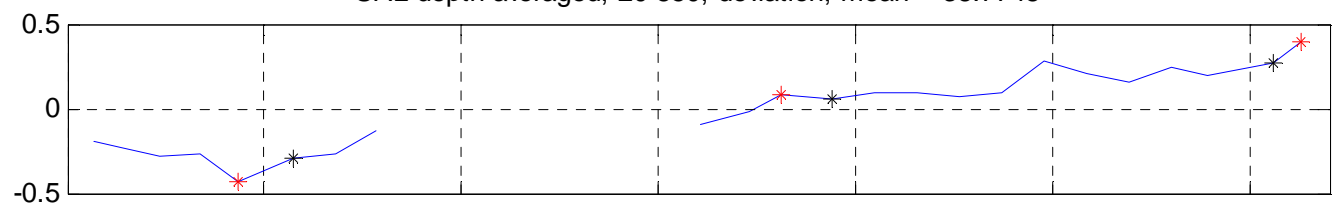

RAU depth averaged, 20-850, deviation; mean $=29.0076 \mathrm{~kg} / \mathrm{m} 3$

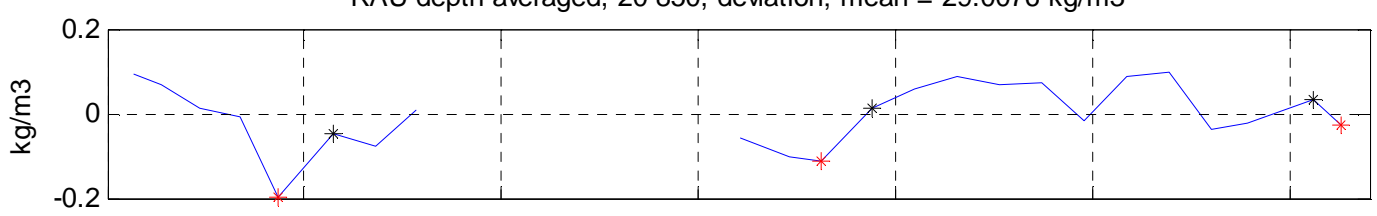

geoflux deviation Sv 20dbars, ref 850 dbarsBOUM section

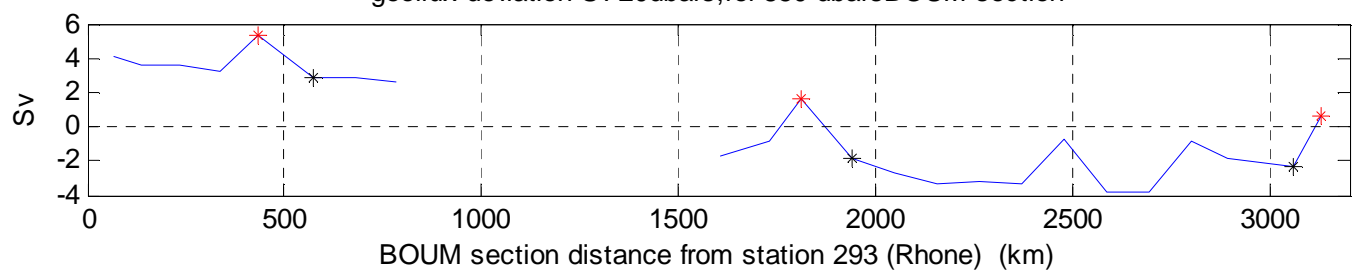

DOC depth averaged $20-500 \mathrm{~m}$ deviation, mean $=50.0957 \mathrm{muM}$

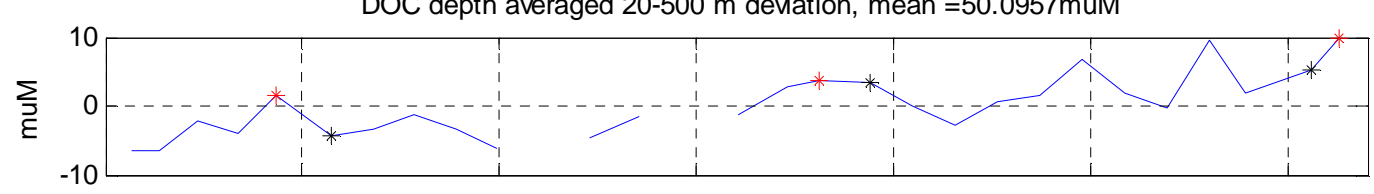

DIC depth averaged 20-500 $\mathrm{m}$ deviation, mean $=2306.8791 \mathrm{muM} / \mathrm{kg}$

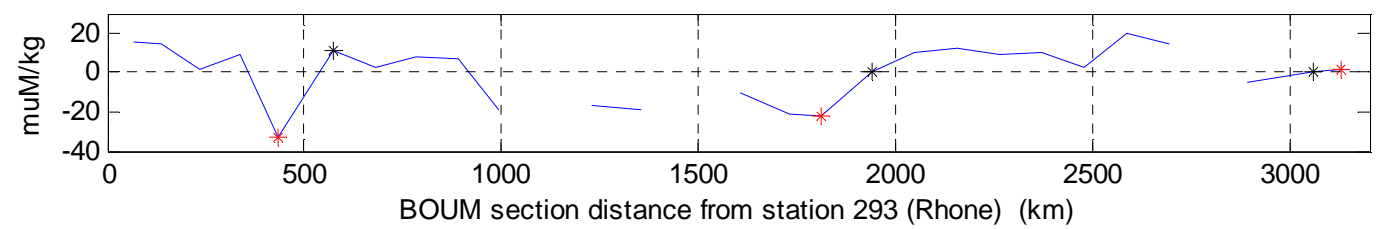

Fig. 7. Deviation between depth-averaged (20-850 dbars) values and the mean depth-averaged values for the whole transect of the following parameters: AOU ( $\left.\mu \mathrm{mol} \mathrm{kg}{ }^{-1}\right) ; S$ (PSU); $\sigma\left(\mathrm{kg} \mathrm{m}^{-3}\right)$; deviation to the mean of the baroclinic geostrophic flux function $F$ (Sv) at 20 dbars when considering a reference depth at 850 dbars ( $0 \mathrm{~Sv})$; deviation of depth-averaged (20-500 dbars) to mean value of dissolved organic carbon (DOC $\mu \mathrm{mol} \mathrm{kg}{ }^{-1}$ ) and dissolved inorganic carbon (DIC $\mu \mathrm{mol} \mathrm{kg}^{-1}$ ) along the BOUM transect. The mean integrated values for the transect are respectively mean $(\mathrm{AOU})=48.2 \mu \mathrm{mol} \mathrm{kg}{ }^{-1}$, mean $(S)=38.775$, mean $(\sigma)=29.008 \mathrm{~kg} \mathrm{~m}^{-3}$, mean $(\mathrm{DOC})=50.1 \mu \mathrm{M}$ and mean $(\mathrm{DIC})=2306.9 \mu \mathrm{mol} \mathrm{kg}-1$. The positions of eddies $\mathrm{A}, \mathrm{B}$, and $\mathrm{C}$ are indicated with red crosses and the positions of the nearest casts are indicated by black crosses. No values were obtained when bottom depths were $<850$ dbars (or $<500$ dbars), as occurred near the Rhône river mouth or in the Sicilian channel.

$-20 \mu \mathrm{mol} \mathrm{kg} \mathrm{k}^{-1}$ below the pycnocline (around $30 \mathrm{~m}$ ) under the influence of the spring net community production which occurs after the stratification of the water column (strong de- celeration of oxygen transfer towards the surface) and the heating by penetrating solar radiation which accounts for a solubility decrease (with $T$ increase) of $10-15 \mu \mathrm{mol} \mathrm{kg}-1$ 
in July in the MS. AOU reaches positive values at approximately the DCMD. This latter depth also corresponds approximately to the W-MLD (Table 1) and to the depth of the top of the nitracline, except in areas of strong W-MLD (northwestern MS and eddy C). The fact that W-MLD corresponds to a depth where AOU is nil (Fig. 6) indicates that lower depths are ventilated during winter with a positive net community production when stratification occurs, whereas deeper depths show $\mathrm{AOU}>0$, indicating more mineralisation than production (negative net community production) for the same period of time (between winter and summer).

\subsubsection{West-east trends and impact of eddies on integrated contents}

Integrated (20-850 dbars) contents were quantified in order to show the deep depth impact of the eddies on physical and biogeochemical variables along the BOUM section (Fig. 7). The three upper panels represent differences between depthaveraged values (20-850 dbars) and the mean values for the whole transect (reported in the title of each panel) for AOU $(\mu \mathrm{mol} \mathrm{kg}-1), S$ and $\sigma\left(\mathrm{kg} \mathrm{m}^{-3}\right)$. The fourth panel shows the variations of the flux function $F$. Each peak of the function $F(\mathrm{X})$ indicates the presence of an anticyclonic eddy between two adjacent stations, or possibly the presence of meanders, but this could be disregarded when considering surface ADCP currents (Fig. 1 bottom). The two lowest panels show integrated DOC $(\mu \mathrm{M})$ and DIC $\left(\mu \mathrm{mol} \mathrm{kg}{ }^{-1}\right)$ using discrete sampling and 10-m interpolation intervals. On each panel, the LD stations A, B and C are marked by red crosses and the closest SD stations by black crosses. The variables (Fig. 7) show trends indicating general features of the MS, and distinctive spikes indicating the presence of eddies and how much regular trends are therefore modified. Mean $S$ increased by more than 0.5 towards the east and reached its maximum value in the Levantine basin, as expected. Overall sea level decreased due to waters below 200 dbar being denser and saltier in the eastern basin than they are in the western basin (Fig. 1 middle). This corresponds to a decreasing trend in flux function as seen in Fig. 7. It is less wellknown that AOU is lower in the east than in the west at the same water level. The trend for DOC is positive with circa $-5 \mu \mathrm{M}$ in the western basin to more than $+5 \mu \mathrm{M}$ in the Levantine basin. Excess density $(\sigma)$ and DIC did not exhibit significant trends. The positions of the LD stations $\mathrm{A}, \mathrm{B}$ and $\mathrm{C}$ are marked by a maximum in $F(\mathrm{X})$ greater than $2 \mathrm{~Sv}$, which indicates a high transport between the eddy centre and the adjacent SD stations, and a circular anticyclonic flow around the axis of the eddy. A decrease in AOU and in $\sigma$, as expected for anticyclonic eddies, was observed at the same locations (Fig. 7). However, a decrease in $S$ was observed at LD station $\mathrm{A}$, while an increase was observed at LD stations B and C: this will be explained later when considering water masses and the structure of each eddy. The transect also crossed eddies that had not been chosen for the process study such as the Ierapetra anticyclonic eddy to the south-east of Crete $(\mathrm{X} \approx 2450 \mathrm{~km})$ with its strong AOU anomaly, and the more easterly $(X \approx 2800 \mathrm{~km})$ Mersa-Matruh eddy. An increase in dissolved organic carbon (DOC) was observed inside each eddy we crossed. This was generally associated with a decrease in dissolved inorganic carbon (DIC) except in the case of eddy C. Almost each spike corresponds to an identified eddy and has a significant value, e.g. $>10 \mu \mathrm{mol} \mathrm{kg} \mathrm{kg}^{-1}$ in $\mathrm{AOU},>1 \mathrm{~Sv}$ in transport. The co-occurrence on each variable of these spikes superimposed on trends, even if some appear relatively weak for some variables, is a strong indication that each of the five identified eddies has a significant impact on physical and biogeochemical trends along the transect.

\subsection{Main characteristics of the three anticyclonic eddies (A, B, and C)}

On board measurements of the mean ADCP currents (Fig. 1, top and bottom), taken along the ship transect at depths between 29 and $125 \mathrm{~m}$, indicate that the three sites were inside anticyclonic eddies. Figure 1 (bottom) provides evidence that locations of the LD stations were near the axis $(<10 \mathrm{~km})$ of the eddies, but drifted with the drift of the centres. Analysis of the drifting of the mooring lines and of the float trajectories (not shown) indicates that the $\mathrm{R} / \mathrm{V}$ was located less than $3 \mathrm{~km}$ from the centres of each eddy at the beginning of the LD stations. Their diameters were close to $100 \mathrm{~km}$ and the studied areas were under $10 \mathrm{~km}$ from the centre of the eddies. The positioning near the centres of anticyclonic eddies is also confirmed by the particular variations of several integrated variables along the BOUM transect (Fig. 7).

The main physical, chemical and dynamical characteristics of the three studied eddies are synthesized in Fig. 8 (middle) and Table 2. Figure 8 shows the superimposed vertical profiles of two casts for each eddy: one cast very close to the eddy axis $(<10 \mathrm{~km}$ from axis, casts 186,114 and 71 for LD stations A, B and C, respectively), which is later called "in" profile, and one cast outside the eddy ( $>70 \mathrm{~km}$ from axis, casts 130, 2 and 17 for SD stations 22, 1 and 11, respectively), which is later called "out" profile. Fig. 8 shows the vertical profiles of $T, S$ and AOU (top), those of the anomalies as will be defined below (middle) and those of primary production, $\mathrm{Chl} a, \sigma_{\theta}, \mathrm{NO}_{3}$ (bottom).

\subsubsection{Dynamical characteristics and anomalies as typical properties of each eddy}

Before presenting the specific characteristics of each eddy (Table 2), we briefly give a reminder of the dynamical specificity of mesoscale anticyclonic eddies. A general description of a typical anticyclonic eddy is presented in SM, Part C. Horizontal anomalies are determined by comparing "in" and "out" depth profiles of all observed parameters.

Horizontal anomalies are conserved inside the body of water around the axis, because it is isolated from mixing and 

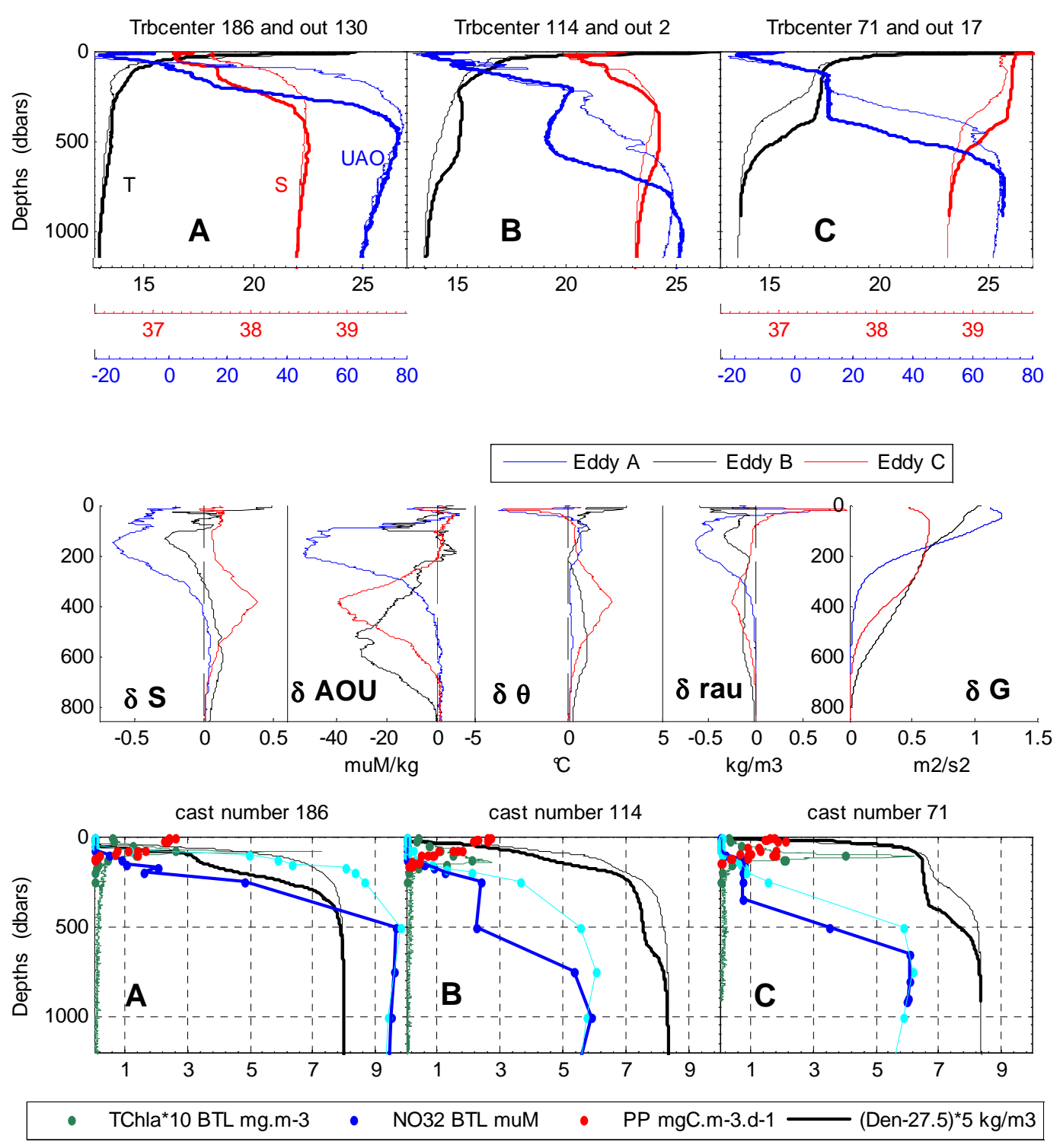

Fig. 8. Top: vertical profiles of $\theta$ ( ${ }^{\circ} \mathrm{C}$ in black), $S$ (PSU in red) and AOU ( $\mu \mathrm{mol} \mathrm{kg}-1$ in blue) vs. pressure $(0-1500 \mathrm{dbars})$ inside the eddies (thick lines; casts 186, 114 and 71 for LD stations A, B and C, respectively) and outside but from the closest SD station (thin lines; casts 130, 2 and 17 for SD stations, respectively). The same scales for each LD station A, B, and C with the corresponding colours are reported below. Middle: vertical profiles of $S$, AOU, $\theta$ and $\mathrm{G}$ anomalies from left to right. Depths of top and bottom anomalies indicated in Table 2 are clearly shown by values close to zero. Bottom: vertical profiles of primary production $\left(*: \mathrm{mgC} \mathrm{m}^{-3} \mathrm{~d}^{-1}\right.$ ), total chlorophyll $a * 10$ (green * for HPLC measurements and - for fluorescence converted measurements: $\left.\mu \mathrm{g} \mathrm{L}^{-1}\right)$ and density $\left((\rho-27.5) * 5,-: \mathrm{kg} \mathrm{m}^{-3}\right) \mathrm{vs}$. pressure (dbars) at the three LD stations (same casts as for Fig. 8 (top) but with rosette sampling except for density). Primary production was measured twice during the LD station occupation. Vertical profiles of nitrate concentration $\left(\mu \mathrm{mol} \mathrm{kg} \mathrm{kg}^{-1}\right.$ ) vs. pressure inside (dark blue $*$ ) and outside (light blue ${ }_{*}$ ) the eddies for the same cast and station as for AOU in the top figure.

advection from surrounding waters during the lifetime of the eddy. This is due to the strong influence of $\zeta$ on potential vorticity conservation (see SM treating the shape of such a body of water). Thus, the so-called anomalies are typical properties of each eddy and are easy to observe from CTD casts. They also provide information about the period and location of the eddy formation. It is interesting to note (Table 2) that inferred $\zeta,<0$, remains a sizeable fraction of $f$ roughly -0.3 to $-0.4 f$, and is of the same magnitude as that observed for meddies, smeddies or swoddies (Pingree and Le Cann 1992, 1993). 


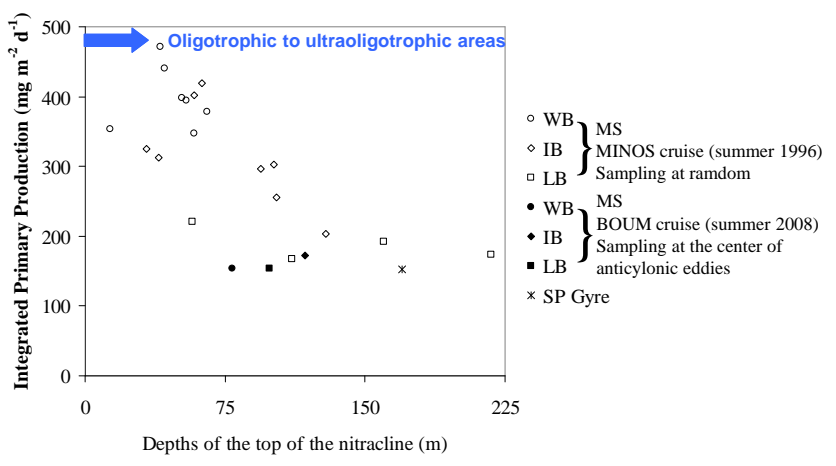

Fig. 9. Integrated primary production vs. depth at the top of the nitracline. Data from the MS in the western basin (WB), the Ionian basin (IB) and the Levantine basin (LB): MINOS cruise (Moutin and Raimbault, 2002) and BOUM cruise, and data from the most oligotrophic area in the world ocean, the South Pacific gyre (SP: T. Moutin, unpublished data).

\subsubsection{Observed anomalies on physical and biogeochemical properties, and time and location during formation}

Table 2 reports, in addition to general properties as $\Delta H$ corresponding to the significant deepening of a specific isopycnal, the extreme values observed as $\delta$ differences between "in" and "out" casts for $\sigma, \theta, S$ and AOU. Figure 8 (middle) shows the depth profiles of each anomaly and the geopotential $(\delta G)$. The maximum anomalies are also indicated and noted, as for example $\sigma_{\text {MaxAno, }}^{E}$, without taking into account the real sign of the anomaly which is $<0$ for $\sigma, \theta$, AOU and $>0$ or $<0$ for $S$. The depths of observed maximum anomalies are also indicated in Table 2 using the depths of maximum density anomalies, without taking into account the possible deviations to real depths for each parameter. These changes are in any case weak (Fig. 8 middle). Higher anomalies appeared on $S$ and AOU, but they are also significant on $\theta$ and $\sigma$.

$\theta-S$ properties of anomalies are indicated in thick red in Fig. 2a and $b$ for the depth range between the top and the maximum of anomalies. This shows that the depth ranges of significant anomalies are in the non-warmed part of the $\theta-S$ diagrams but not far beneath this. However, in the case of eddy $\mathrm{B}$, it appeared that 2 eddies were positioned one above the other. These 2 parts of eddy $B$ were named $B_{\text {surf }}$ and $B_{\text {deep }}$ for convenience. The maximum depths of anomalies correspond to the densest waters and the lower extremities. These extremities are close (at least for $\mathrm{B}_{\text {deep }}$ and C) to the $\theta-S$ properties of the "out" station but with a difference in depth of $\Delta H \mathrm{~m}$. These anomalies are on the ochre dotted line representative of LIW (Fig. 2b) for eddies $C$ and $B_{\text {deep }}$, and in the range of winter modified Atlantic water (MAW) $\theta-S$ properties for eddies $A$ and $B_{\text {surf }}$. These are indications that all three eddies formed during a winter period.
Anomalies also help to locate the eddies during the winter of their formation. Eddy $\mathrm{C}$ probably formed at the same location it occupied during summer 2008 because, at the maximum anomaly depth, $\theta-S$ properties correspond to the saltiest and warmest limits known for LIW (Fig. 2). However, the characteristics of the anomalies for $\mathrm{B}_{\text {deep }}$ cannot correspond to the winter 2008 location, where estimated W-MLD reached only $109 \mathrm{~m}$ (Table 2), or about $200 \mathrm{~m}$ above the observed depth range of the $\mathrm{B}_{\text {deep }}$ anomaly. Indeed, $\theta-S$ characteristics at $\mathrm{D}_{\text {MaxAno }}^{E}$ indicate that eddy formation may have occurred in the northern part of the Ionian basin, near the eastern Greek coast (Pelops area). The deep eddy B formed in winter before 2008, as confirmed by low $\mathrm{AOU}_{\text {MaxAno }}^{E}$ value near $20 \mu \mathrm{M}$, which indicates recent ventilation when compared to the station "out" value of circa $50 \mu \mathrm{M}$ at the same depth $\left(\mathrm{D}_{\text {MaxAno }}^{E}=600 \mathrm{dbars}\right)$. The strong $\delta \mathrm{AOU}^{E}$ of around $-30 \mu \mathrm{M}$ observed in summer 2008 is consistent with the drifting of the eddy since its formation southwestwards into an area where the water is older. A $400 \mathrm{~km}$ drift probably took more than a year, but its exact duration cannot be estimated at present. Eddy $\mathrm{B}_{\text {surf }}$ formed with MAW, and the $\delta \mathrm{AOU}^{E}$ value is consistent with the formation, or at least ventilation, during winter 2008 when considering W-MLD 2008. Such trapping of surface outer water by an eddy, and intensification of the dynamic properties of an existing deep eddy, cannot be discussed here, but it is probably linked to an interaction between the eddy and the MAW jet. Eddy A clearly formed with MAW generally observed in the Algerian basin and possibly during winter 2008, considering the low AOU at depth and $\theta-S$ properties of anomalies. This eddy is the least deep of the three studied.

One main concern for biological and biogeochemical studies and budgets is to know if eddies can be considered as horizontally closed systems dating back to the previous winter, in particular close to the surface. If anomalies in the $0-100 \mathrm{~m}$ range are weak, the main dynamical properties, relative vorticity, geopotential (see $\delta G$, Fig. 8 middle), are still different from the outer part of the eddies and a potential vorticity barrier up to the warmed surface subsists. As already observed by Chapman and Nof (1988), this vorticity barrier prevents any strong mixing and advection of outer water inside the eddy and explains why the depth range of eddies starts from the surface (Table 2 and SM Part C).

The core of each eddy was found at depth (Table 2) where large differences between "in" and "out" casts for $S$ and AOU were observed (Fig. 8 top). At the centre of each eddy, a distinct pycnostad was observed which showed very little $S$ change against depth (100-250, 300-600, 150-380 dbars for LD stations A, B, C, respectively). Nevertheless, a slight stratification remains inside the core of the eddies, as is shown by the non-zero $T$ and $S$ vertical gradients. However, for the same depths, AOU is constant (eddy C), slightly decreasing (eddy B) or slightly increasing (eddy A) while a regular and more classical AOU increase outside the eddies was observed. Below the deeper depth of the core, stratification 

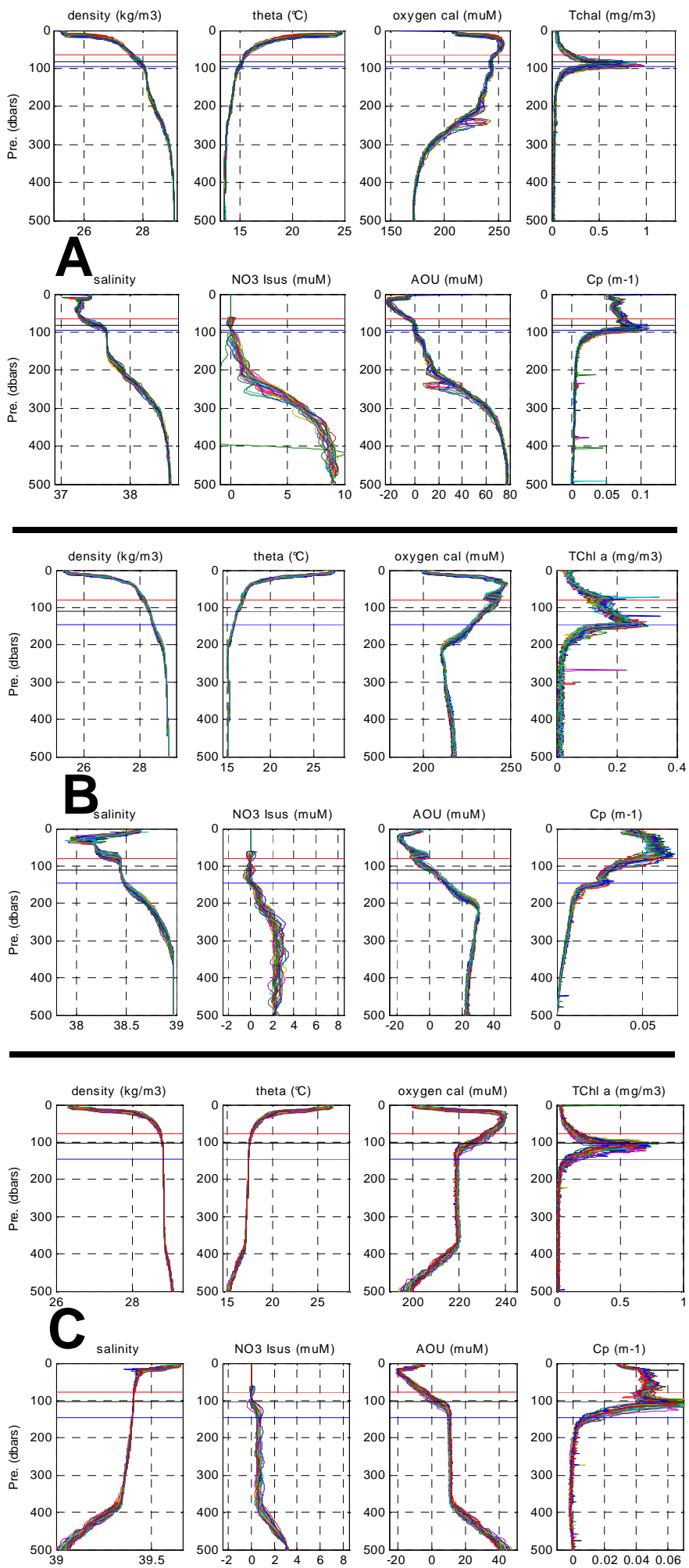

Fig. 10. Superposition of all vertical profiles vs. depth ( $0-500$ dbars) obtained during occupation of the LD stations A, B, and C in uppermost position and from left to right: $\sigma\left(\mathrm{kg} \mathrm{m}^{-3}\right), \theta\left({ }^{\circ} \mathrm{C}\right), \mathrm{O}_{2}\left(\mu \mathrm{mol} \mathrm{kg}{ }^{-1}\right), T \mathrm{chl} a\left(\mathrm{mg} \mathrm{m}^{-3}\right)$, and in lower position: $S$ (PSU), ISUS nitrate concentration $(\mu \mathrm{M})$, AOU $\left(\mu \mathrm{mol} \mathrm{kg}{ }^{-1}\right)$ and $C p\left(\mathrm{~m}^{-1}\right)$. The best $\mathrm{x}$-axis scale is chosen for each station. The 3,1 and $0.3 \%$ of incident light level were reported on each graph using horizontal lines in red, green and blue, respectively. 
TChl a
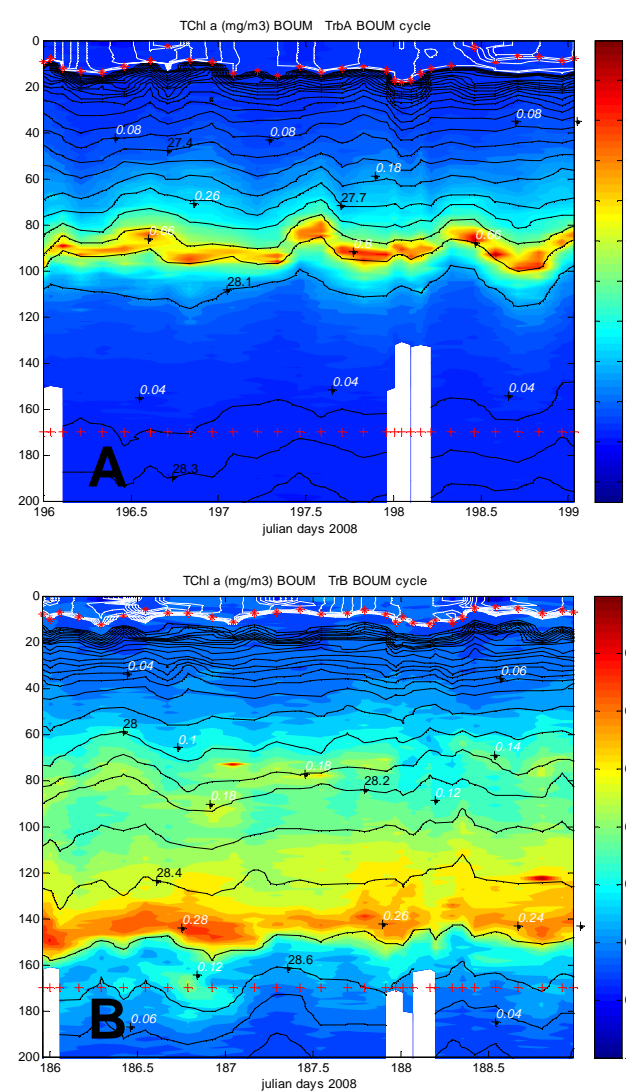

TChl a (mg/m3) BOUM TrbC BOUM cycle

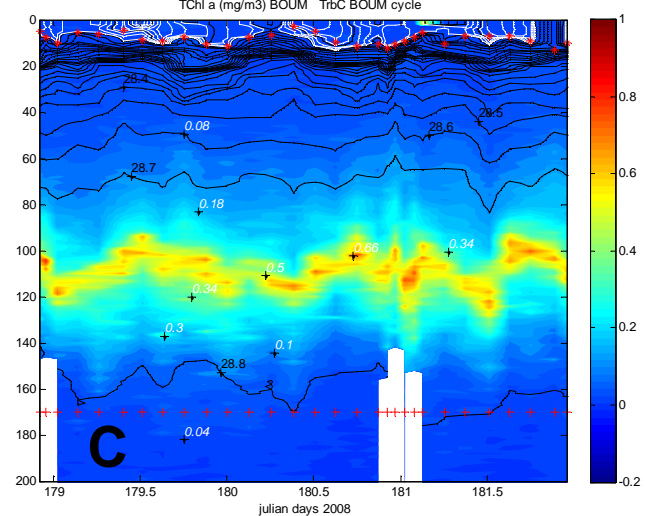

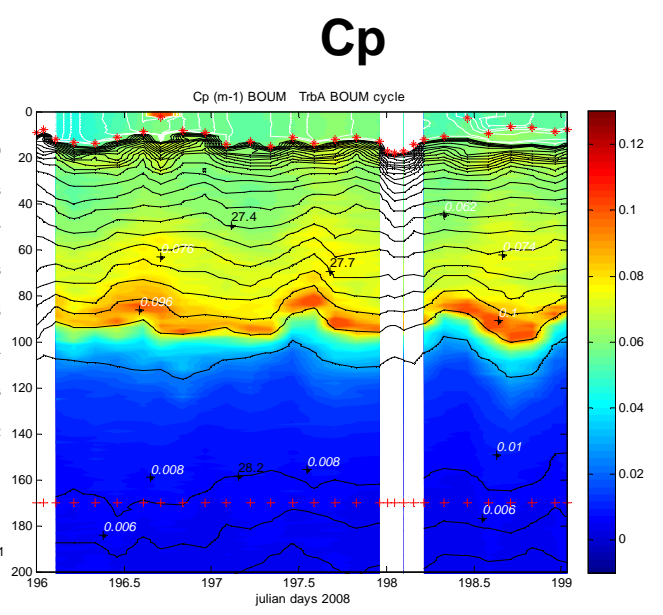

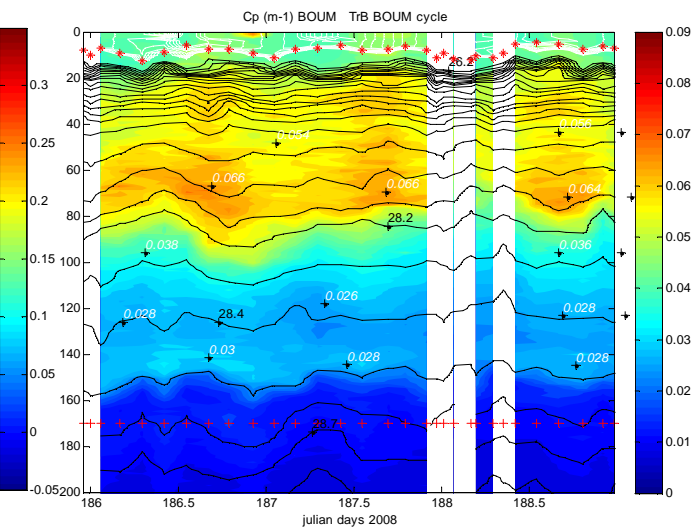

julian days 2008

Cp (m-1) BOUM TrbC BOUM cycle

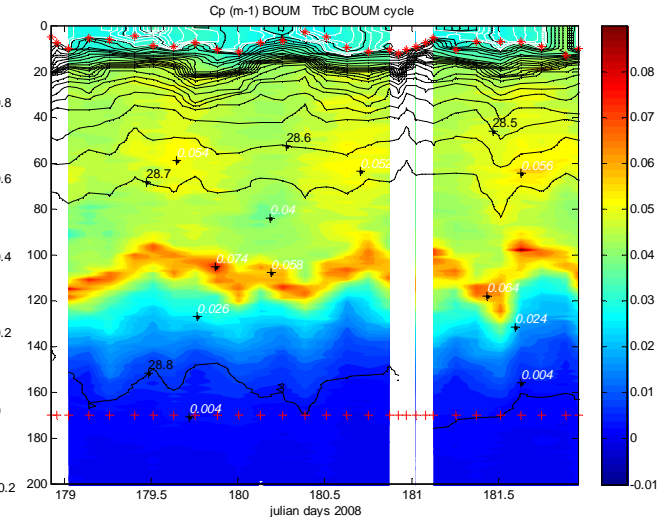

Fig. 11. Temporal sections between $0-200 \mathrm{~m}$ depth for $T \mathrm{chl} a\left(\mathrm{mg} \mathrm{m}^{-3}\right)$ and for the optical attenuation coefficient $C p\left(\mathrm{~m}^{-1}\right)$ for the particles at the LD stations A (top), B (middle) and C (bottom). The dates on the x-axis are in 2008 Julian days, and the dates of the profiles are indicated by red crosses near 170 dbars. The red stars indicate $\mathrm{MLD}_{0.03}$. Some values are indicated in white. The fine black lines are the isopycnals drawn each at $0.1 \mathrm{~kg} \mathrm{~m}^{-3}$ intervals. The white lines in the upper part of each panel are the isopycnals drawn each at $0.01 \mathrm{~kg} \mathrm{~m}^{-3}$ intervals.

(vertical gradient of density) increases and the vertical gradients of the other variables are stronger than outside the eddies, so that the profiles of each variable are virtually the same below a certain depth which can be considered as the bottom of the eddy $\left(\mathrm{D}_{\text {BotAno }}^{E}: 420,1200\right.$ and $800 \mathrm{~m}$ for $\mathrm{LD}$ stations $\mathrm{A}, \mathrm{B}$ and $\mathrm{C}$, respectively). The influence of the eddies could be much deeper, and different depths were obtained when small dynamic anomalies were considered (Table 2) or fine-scale changes in AOU (Fig. 4).

Primary production rates were higher close to the surface and decreased down to zero at, or just below, the euphotic zone depth (Fig. 8 bottom). The top of the nitracline 
corresponds to the DCMD at each station. A main nitracline, related to the W-MLD (Table 1), was observed at LD station C. As previously noted, the upper nitracline is related to the equilibrium between biological production and export occurring after the previous winter mixing. Although discrete sampling was relatively sparse at depth, similar profiles were observed for nitrate concentration with relatively low variations (changes in the vertical gradients) observed inside the cores of the eddies. Noteworthy identical differences between profiles from inside and outside the eddies were observed for nitrate concentration and AOU. This result is probably related to remineralisation, leading to the same ratios between oxygen consumption and nitrate production (Redfield et al., 1963). Less or even no organic matter was remineralised inside the cores of the eddies, either because of less or even no organic matter input, or because of lack of time for mineralisation. The deeper DCM (Fig. 8 bottom) and lower integrated chlorophyll $a$ concentration between $0-150 \mathrm{~m}$ (Table 1), indicators of a stronger oligotrophy, are found inside eddy B in the Ionian basin and not, as expected, in the Levantine basin of the MS. The EZD reaches $104 \pm 4 \mathrm{~m}$ at a maximum value inside the Ionian area at LD station B. Integrated mean primary productions measured in situ inside the three studied eddies, A, B and C, were 160,190 and $164 \mathrm{mgC} \mathrm{m}^{-2} \mathrm{~d}^{-1}$ (Christaki et al., 2011), for a nitracline depth of 72, 114 and $93 \mathrm{~m}$, respectively (Fig. 9). The results confirm the previous conclusion that IPP about $150 \mathrm{mgC} \mathrm{m}^{-2} \mathrm{~d}^{-1}$ (obtained using 24-h in situ incubation from dusk-to-dusk, as recommended by JGOFS) may appear as a lower limit for IPP during strong oligotrophic conditions (Moutin and Raimbault, 2002). The influence of eddy A, even located in the western basin of the MS, was to lower the primary production to a level comparable to the one measured inside eddy $\mathrm{C}$, in the extreme east of the MS. The mesoscale activity is strong enough to delete (or even reverse) the very well-known western to eastern gradient of trophic conditions in the MS.

\subsubsection{Short-term temporal trends}

LD stations A, B and C were occupied for 4 days, allowing the study of short-term variations in biogeochemical properties using CTD casts undertaken every $3 \mathrm{~h}$. A total of 32 , 33 and 32 casts were performed for LD stations A, B and C, respectively. Figure 10 shows the superposition of all vertical profiles vs. depth (dbars) of $\sigma\left(\mathrm{kg} \mathrm{m}^{-3}\right), \theta\left({ }^{\circ} \mathrm{C}\right), \mathrm{O}_{2}$ $\left(\mu \mathrm{mol} \mathrm{kg}{ }^{-1}\right)$, total chl $a\left(\mathrm{mg} \mathrm{m}^{-3}\right), S$ (PSU), ISUS nitrate concentration $(\mu \mathrm{M})$, AOU $\left(\mu \mathrm{mol} \mathrm{kg}{ }^{-1}\right)$ and $C p\left(\mathrm{~m}^{-1}\right)$, obtained at LD stations A, B, C. The first observation to note is the very low variability between each profile (of about 30 ) as is expected from stations located in the centre of anticyclonic eddies. This gives us confidence in comparing "in" and "out" profiles, as previously described (Fig. 8). The properties of the cores are shown by a break on the vertical gradients in $\sigma, \theta$ and $S$ for specific depths (Table 2). A maximum in $\mathrm{O}_{2}$ and corresponding minimum in AOU (which may even be negative) were observed between $40-60 \mathrm{~m}$ just beneath the surface thermocline while $\mathrm{O}_{2}$ in the upper surface water was close to saturation (around $2 \%$ ). As indicated above, the oxygen and nitrate concentrations were remarkably constant in the core of eddy $\mathrm{C}$, although this was not the case for density between 120 and $380 \mathrm{~m}$. The same pattern was observed for the deep core of eddy B $(300-600 \mathrm{~m})$. The main nitracline was only encountered at the base of the core of each eddy, 200, 650 and $380 \mathrm{~m}$ and between depths $\mathrm{D}_{\text {MaxAno }}^{E}$ and $\mathrm{D}_{\text {BotAno }}^{E}$ for $\mathrm{LD}$ stations $\mathrm{A}, \mathrm{B}$ and $\mathrm{C}$, respectively. For LD station $\mathrm{B}$, this latter depth was $>500$ dbars and only low $\mathrm{NO}_{3}$ values were observable on the ISUS profile (Fig. 10). Below

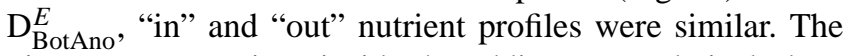
nitrate concentrations inside the eddies were relatively low, $1.0,2.1$ and $0.8 \mu \mathrm{M}$ for LD stations A, B and C, respectively. As a consequence, a secondary nutricline was encountered at the top of the cores, reaching the upper surface waters with their classically zero nitrate concentration.

Maximum total chl $a$ concentration reached $0.92,0.29$ and $0.70 \mu \mathrm{L} \mathrm{L}^{-1}$ for LD stations A, B and C, respectively, with variations in concentration reaching $30 \%$ for the different casts. The depths of the maximum of $T \operatorname{chl} a$ concentrations corresponded to the $1 \%$ of incident light level, except for eddy B $(0.3 \%)$. This may be related to an artefact in the conversion between fluorescence and concentration, as explained at the end of this section.

Figure 11 represents the temporal sections between 0 $200 \mathrm{~m}$ depth of $T \mathrm{chl} a\left(\mathrm{mg} \mathrm{m}^{-3}\right)$ and of the optical attenuation coefficient $C p\left(\mathrm{~m}^{-1}\right)$ for the particles. The temporal scale on the $\mathrm{x}$-axis is given in 2008 Julian days, and the dates of the profiles are indicated by red crosses near 170 dbars. On each panel, isopycnals $\left(\sigma_{\theta}\right)$ are drawn with thin black lines at $0.1 \mathrm{~kg} \mathrm{~m}^{-3}$ intervals in deeper layers from 25.7, 26.2 and 26.4 for LD stations A, B and C, respectively, and with white lines at intervals of $0.03 \mathrm{~kg} \mathrm{~m}^{-3}$ near the surface in the range [25.21-25.39], [25.31-25.61] and [26.30-26.48] for LD stations A, B and C, respectively. The daily changes in density of the mixed layers are clearly visible. In addition, the $\mathrm{MLD}_{0.03}$ are plotted as red stars. The temporal variations of $T \mathrm{chl} a$ and $C p$ (Fig. 11) are in good agreement, indicating maxima of phytoplankton biomass and of particles at the same depths, 90, 75 and 110 dbars for LD stations A, B and $\mathrm{C}$, respectively. The depths of these maxima fluctuate with the same temporal periodicity as for isopycnals, suggesting an influence of $\pm 10 \mathrm{~m}$ of near-inertial internal waves. The amplitude of the waves varied against depth, as is shown by the vertical oscillations of the isopycnals, and was particularly low along strong density gradients (pycnocline and thermocline) as well as inside the core of the eddies. The internal waves also have an influence on the $\mathrm{MLD}_{2 \mathrm{~d}}$ (red crosses in Fig. 11). These depths reached minimum values between $0-$ $4 \mathrm{~h}$ local time during the night, i.e. when buoyancy fluxes were negative. The surface layer $0-\mathrm{MLD}_{2 \mathrm{~d}}$ was often slightly stratified due to diurnal heating, which could be lost during 
night, as it could be seen by looking closely to the thin white isopycnals drawn each $0.01 \mathrm{~kg} \mathrm{~m}^{-3}$ above the main pycnocline.

A distinct diurnal maximum in $C p$ occurred between 12$16 \mathrm{~h}$ local time above the DCM.

At LD station B (and nearby SD stations), a maximum of $T \operatorname{chl} a$ was observed at $135 \mathrm{~m}$ depth despite there being no observed variations in $C p$. This is probably related to divinyl chl $a$ fluorescence associated with prochlorococcus spp. populations, because maxima of $\operatorname{chl} b$ and of zeaxanthine were also observed at the same depth (data not shown). When considering bottle measurements instead of the $T \mathrm{chl} a$ estimated from the fluorescence, no $T \mathrm{chl} a$ maximum was observed at $135 \mathrm{~m}$ depth (Fig. 8 bottom) and only one was observed at $113 \mathrm{~m}$ which is why this maximum should be considered as an artefact in the conversion of fluorescence units to $T \operatorname{chl} a$ concentration.

\subsection{First-order daily N-budget at the LD stations}

A first-order daily N-budget was carried out at the three LD stations (Table 4 ). Inputs by eddy diffusion and $\mathrm{N}_{2}$ fixation are virtually identical at $\mathrm{LD}$ stations $\mathrm{A}$ and $\mathrm{B}$, whereas $\mathrm{N}_{2}$ fixation is definitely weaker at the eastern LD station C. This result is discussed by Bonnet et al. (2011). N-input by $\mathrm{N}_{2}$ fixation during the strongly stratified period in LD stations A and B may represent a significant part (up to $32.3 \%$ ) of new production, a percentage close to previous estimations in oligotrophic areas (Karl et al., 2002). N-input by diffusion is of the same magnitude as input by nitrogen fixation (10$20 \mu \mathrm{mol} \mathrm{m} \mathrm{m}^{-2} \mathrm{~d}^{-1}$ ) except in the eastern eddy $\mathrm{C}$ where they are largely higher. The estimated atmospheric deposits are higher or of the same magnitude as input by diffusion. The new $\mathrm{N}$-input in the photic zone is close to the $\mathrm{N}$-export measured at $230 \mathrm{~m}$ by drifting traps. We found an export/GPP close to $1 \%$ and a regenerated production/GPP around $99 \%$ with a sum slightly below $100 \%$.

\section{Discussion}

The following discussion will concern specific points chosen in order to better characterize the influence of eddies on the physics and biogeochemistry of the MS. The method and the results of W-MLD determination will be discussed in Sect. 4.1. The deep waters, the characteristics of the LIW, and $\mathrm{N}: \mathrm{P}$ ratio will be discussed in Sect. 4.2. Then, the characteristics and specificity of the eddies studied during the BOUM cruise and budgets will be discussed in Sect. 4.3.

\subsection{The winter mixed layer depth (W-MLD) to understand pycnostad formation and biogeochemical anomalies in the cores of eddies}

In this paper, we introduce results of W-MLD estimates (Table 1, Fig. 3) obtained from the LTMLD (lagged time mixed layer depth) method described in SM (Part B). These values are important because they give us a better understanding of pycnostad formation, and of strong biogeochemical anomalies that occur in the cores of the eddies. Most eddies discussed here are thought to have formed during winter by a surface jet instability which induces an accumulation of less dense water. The consequence is a higher W-MLD near the eddies' axes. The W-MLD was effectively greater inside the anticyclonic eddies than outside (Table 1 and Fig. $3 \mathrm{~b}$ where W-MLD are also reported). W-MLD at the LD station C in the easternmost study area of the MS reached $400 \mathrm{~m}$, more than twice as deep as the $150 \mathrm{~m} \mathrm{W-MLD}$ found at the nearest SD station outside the eddy. The method gives an estimate of the depth of the mixed layer at its maximum over the year, therefore before mixed layer retreat during spring. When the mixed layer is withdrawn, a homogeneous layer (pycnostad) subsists under the new MLD which is then isolated from atmospheric influence. However, the estimates rely only on a CTD profile measurements undertaken in the summer, and on the quantity of buoyancy that was retained by the ocean from atmosphere-ocean fluxes since the period of maximum mixed layer (see SM). There are several ways to evaluate the LTMLD method, i.e. to test the quality of the W-MLD estimate.

The first way is to check whether the depths found are coherent with any independently known winter properties, such as the winter sea surface temperature (W-SST). W-SST is used for surface flux calculations (ECMWF model), and temperatures observed in summer at W-MLD generally correspond. W-SST varied between 12.7 and 17.4 along the section, similar to temperatures at W-MLD (not shown), and the standard deviation (sd) of the temperature difference between these two datasets for the 30 stations studied was $<0.8^{\circ} \mathrm{C}$. The comparison is even better, and sd falls below $0.45^{\circ} \mathrm{C}$ when data in the Sicilian channel area are discarded. This result can be expected as the W-MLD method is less precise in areas with strong horizontal advection.

Another way to evaluate the W-MLD estimates is to compare the MLD near and around the axis of an eddy. Indeed, a recently formed eddy has a higher MLD close to its axis because of surface water accumulation during its formation. This observation is made for all five eddies crossed along the section (Fig. 3b). The depth difference is rather weak for $\mathrm{B}_{\text {sup }}$, but this is probably because $\mathrm{B}_{\text {sup }}$ is only a part of eddy B.

Thirdly, the observed coincidence of different depths (outside the eddies), the top nitracline depth $\left(\mathrm{D}_{\mathrm{NO}_{3}}\right)$, the EZD, the nil AOU depth and the W-MLD (Fig. 6), gives confidence to the LTMLD method. During winter, the upper part of the water column, between the surface and the W-MLD, is ventilated and therefore has an $\mathrm{AOU}=0$. Nitrate concentration may be nil or higher depending on whether or not the mixed layer reaches the previous year's nitracline. The EZD is a priori slightly higher than during summer. It is known that surface chl $a$ reaches a maximum during winter (D'Ortenzio and 
Ribera d'Alcala, 2009) outside the northwestern MS. Then, the following two cases can be considered.

1. Outside the eddies, $\mathrm{D}_{\mathrm{NO}_{3}}$ is determined by nitrate biological assimilation during the spring-summer-autumn period, and a $\mathrm{D}_{\mathrm{NO}_{3}}$ near the beginning of winter EZD is expected for a stratified ocean. If, during winter, WMLD is lower than $\mathrm{D}_{\mathrm{NO}_{3}}$, there is no new supply of nitrate into the photic zone and the oligotrophic status of the system will increase, even if primary production may temporarily increase because of increasing irradiance following the winter solstice (Behrenfeld, 2010; Chiswell, 2011). The dissolved organic matter, which accumulates during upper water column stratification, is then distributed in the W-MLD layer. If W-MLD is (slightly) higher than $\mathrm{D}_{\mathrm{NO}_{3}}$, there is a new supply of nitrate into the photic zone and a new primary production with a new export towards deeper depths. Therefore, $\mathrm{D}_{\mathrm{NO}_{3}}$ deepens limiting the following new nitrate supply. In both cases, there is a coincidence between the WMLD, $\mathrm{D}_{\mathrm{NO}_{3}}$, the EZD and the nil AOU depth, because the upper water column is ventilated during winter.

2. Inside an eddy core formed during winter, water less dense and exhausted in nutrients accumulates. $\mathrm{D}_{\mathrm{NO}_{3}}$ and W-MLD are similar and are both higher than EZD which has little seasonal variation. The winter nil AOU depth is also similar to W-MLD. After the retreat of the winter mixed layer during spring, the layer between the EZD and the W-MLD is aphotic and the winter and/or spring production becomes (partly) mineralized, and the isolated dissolved organic matter becomes (partly) preserved. A pycnostad forms as well as a secondary nitracline at the depth of the EZD which coincides with the top of the pycnostad. The main nitracline appears at the bottom of the eddy core. Nutrient concentrations and AOU may increase slightly inside this aphotic pycnostad layer if the particles formed in the above photic layer are sufficiently large to be exported and mineralized there, but not too large to be exported and mineralized deeper. The system will tend toward (ultra) oligotrophy only if nutrient supply to the photic zone is not annual, i.e. only certain years depending on the inter-annual variability of atmosphere-ocean fluxes essentially during winter.

The simplified description of this phenomenon explains the coincidence between the different characteristic depths found outside of the eddies, and outside of the northwestern MS where the W-MLDs are higher than the EZD. It also explains the pycnostad formation with low AOU values, low nutrient concentrations and relatively high dissolved organic matter concentration inside the eddies. This description is in concord with previous observations of the Cyprus eddy in 1989 (Krom et al., 1992). The latter authors described an annual cycle with a new supply of nutrients to the photic zone from the main nitracline (situated at a depth deeper than $400 \mathrm{~m}$ ) at a date before their winter observation in February (date not given). They calculate a nutrient supply for the mixed layer in order to estimate an annual N-budget for the eddy. However, the annual budget will depend drastically upon the pre-existence or not of the eddy at the beginning of winter. Was the eddy already formed before the first observation of Krom et al. (1992)? (i.e. did the secondary nitracline preexist?) The answer is not clear even if the new nutrient supply depends on whether the W-MLD will reach the main nitracline.

Finally, confirmation of the good W-MLD estimate using the LTMLD method is given by the observation of the ARGO float 6900679 (Moutin et al., 2012) which stayed inside eddy C until the end of February 2009. The 2009 W-MLD, estimated from the same depth profile as used for the 2008 W-MLD determination, was $400 \mathrm{~m}$ with the LTMLD method and $350 \mathrm{~m}$ observed with the float on the 2 of March 2009. The error is only around $15 \%$.

\subsection{Recent changes in deep waters, evidence of LIW formation in the core of the Cyprus eddy and of a constant $N^{*}$ value in the whole deep MS}

The extended $\theta-S$ diagrams confirm some recent changes observed in the deep waters of the MS. Roether et al. (2007) showed the impact of the EMT which replaced, in the early 1990s, the fresher and colder EMDW of Adriatic origin (here old EMDW) with saltier and warmer EMDW of Aegean origin of which Lev DW is a remnant (Fig. 2d). Then, the ancient EMDW (old EMDW) was lifted up, and the isopycnal separation of the two deep waters was near $29.18 \mathrm{~kg} \mathrm{~m}^{-3}$, as observed in this study (Fig. 2d) and marked by minima of $\theta$ and $S$ near 1200 dbars in the Levantine basin (Fig. 4a, b). However, these minima were not observed in the Ionian basin (Fig. 2d) because the water had been replaced by new Ionian deep water of Adriatic origin (Ion EMDW), as observed by Rubino and Hainbucher (2007) in winter 2007. This new deep water was, however, saltier and warmer than the old EMDW, and the shoulder observed near 13.5-38.735 on the $\theta-S$ diagram marks this transition. These changes also explain the minimum in oxygen along the 29.17 isopycnal near 1000 dbars (Fig. 4c) which is in the old EMDW and, as the oldest water, has a maximum in AOU in the whole eastern MS (Fig. 4d) at near constant $S$ values. In the western MS, similar changes between old and new WMDW are apparent, but, since the event of a huge amount of 2005-2006 new deep water (Schroeder et al., 2008, CIESM 2009), the interface between the old and new deep waters is marked there by the $29.106 \mathrm{~kg} \mathrm{~m}^{-3}$ isopycnal (Fig. 2c). These critical isopycnal interfaces in the eastern and western MS are also shown to be the interfaces where deep vertical diffusive coefficients abruptly change (Cuypers et al., 2012).

Our results concerning the intermediate layer need to be discussed. Several water masses, of which the LIW is the 
better known, lie on this layer. Similar $\theta$ and $S$ sections to those observed during the BOUM experiment (Fig. 4) were reported by Wüst (1961) from the Strait of Gibraltar to Asia minor before the 1960s. Using more than 600 bottle casts, Wüst (1961) found a salinity maximum of not more than 39.1 in the upper $200 \mathrm{~m}$ layer of the Levantine basin during winter, and a progressive LIW deepening to near $250 \mathrm{~m}$ towards the Strait of Sicily, with a constant depth progression defined by sub-surface $S$ maximum towards the Strait of Gibraltar. The area of LIW formation was already known as the cyclonic Rhodes gyre in the northern part of the Levantine basin, and Wüst (1961) considered the following source properties for LIW, $15.5^{\circ} \mathrm{C}, 39.1$ and $29.06 \mathrm{~kg} \mathrm{~m}^{-3}$ for $\theta, S$ and $\sigma$ respectively. LIW was also assumed to expand along the 29.06 isopycnal. The main path of the LIW is now known to follow the northern slope of deep eastern Mediterranean waters (south Crete, west Greece, west Macedonia, south-east Italy and Strait of Sicily), as drawn by Millot and Taupier-Letage (2005). Lascaratos et al. (1999) reviewed the changes in the intermediate layers induced by the EMT, and also presented full sections through the eastern MS from data before 1999. The latter authors indicated that the baroclinic eddies play an important role in the intermediate layer by spreading LIW and CIW off the northern coasts of the eastern MS. However, a drastic atmospheric change was invoked to explain the formation of a huge amount of CIW, which originates from the saltier and warmer summer Levantine surface water (LSW) entering the Aegean basin. Brenner (1993) provided evidence for the quasi-permanent presence of a Cyprus eddy in the south-east of the Cyprus island for more than 2.5 years in 1988-1990 with core properties increasing in temperature from $16.44^{\circ} \mathrm{C}$ to $16.68^{\circ} \mathrm{C}$, in salinity from 39.08 to 39.27 , and in density but weakly from 28.80 to $28.88 \mathrm{~kg} \mathrm{~m}^{-3}$. We think that such an eddy found in the wake of the Eratosthenes Seamount was similar to eddy $\mathrm{C}$ observed above the Eratosthenes Seamount, but in summer 2008 the core properties were exceptionally warmer and saltier $\left(17.2^{\circ} \mathrm{C}, 39.39\right.$, $28.84 \mathrm{~kg} \mathrm{~m}^{-3}$ ). In addition, there were no minima in $S$ and $T$ between the core near the axis of eddy C and the LSW (Fig. 2b) making sense to increase the $T$ and $S$ properties of W-MLD by mixing core water with summer LSW. As previously described, a W-MLD of $380 \mathrm{~m}$ with properties similar to those of 2008, but slightly saltier and warmer, was effectively measured during winter 2009 by the Argo float. In this context, we believe that an event of LIW formation occurred in eddy $\mathrm{C}$ during the winter before the BOUM cruise. This would explain the recent ventilation marked by the low AOU value $(8 \mu \mathrm{M})$ observed in the eddy core: the $2008 \mathrm{~W}$ MLD was much deeper than the depth of summer $S_{\max }$ when only depths where $T<17.5^{\circ} \mathrm{C}$ were considered in order to avoid the near surface increase of $S$ by evaporation during the spring heating (Fig. 3a, b). The water formed, called ILIW (Fig. 2b), was for that reason one end of the ochre line which symbolizes the change in $T$ and $S$ at $S_{\max }$, when going from eddy $\mathrm{C}$ to the Strait of Sicily. The properties of the
Cyprus eddy core (Brenner, 1993) are not far from this line but clearly fresher and colder. We consider here that eddy C core properties could be considered as LIW properties (i.e. that ILIW is a variety of LIW), because this water was observed too deep to be LSW. It is observed in the Levantine basin but not in the Rhodes gyre, and it is observed below the $17.5^{\circ} \mathrm{C}$ isotherm which means under the seasonal thermocline. This new ILIW could not greatly modify the LIW characteristics for the whole Levantine basin due to its relatively low volume. It happened, for example, when the eddy disappeared in March 2009, as seen from the trajectory of the float 6900679. ILIW formation should nevertheless be considered as a potential factor able to modify the characteristics of LIW formation in the Rhodes gyre during the following winter. Then, along the northern path of LIW where W-MLD may reach $>400 \mathrm{~m}$ (D'Ortenzio and Prieur, 2012, their Fig. 5c), characteristics of LIW could decrease in temperature and salinity each winter due to possible ventilation and vertical mixing with colder and fresher surface water. The new characteristics, weaker AOU and higher density will depend on the W-MLD. The modified LIW could be partially trapped in different new eddies from place to place, and transported towards the south, thus filling the different basins by following the trajectories of eddies (Wu and Haines, 1996). Argo float trajectories from the north to the south were recently observed in this area (Menna and Poulain, 2010). This scenario is not yet proven but is consistent with the properties found in the core of eddy $B_{\text {deep }}$, constituted undoubtedly by LIW water relatively and recently ventilated considering the AOU anomaly. Finally, each eddy disappears dispersing its anomalies in the vicinity along isopycnals (Malanotte-Rizzoli et al., 1999). This scenario could also explain the curious step-like decreasing in $S_{\max }$ and increasing in AOU at $S_{\max }$ observed from basin to basin in the eastern MS (Fig. 3). It explains why the ochre line in Fig. 2a and b, assumed here to represent the LIW core layer, is not isopycnal. It is essentially because, during its progression towards the Ionian basin, the LIW northern path (out of the BOUM section) probably underwent several ventilations and mixings with winter surface waters. In summary, the spreading of LIW core, defined as $S_{\max }$ on vertical profiles, would no longer be isopycnal as previously assumed by Wüst (1961), but density may increase due to some localized ventilations along the northern path, and LIW spreading from eddies towards the interior of the different basins.

Another drastic change appeared on LIW core before the Strait of Sicily ( $X=1600 \mathrm{~km}$, Fig. 3a, c and Fig. 4). $\mathrm{AOU}\left(S_{\max }\right)$ and $\mathrm{AOU}_{\mathrm{Max}}$ values converge near $60 \mu \mathrm{M}$, as $S\left(\mathrm{AOU}_{\mathrm{Max}}\right)$ and $S_{\max }$ are near 38.8. This could be explained both by the convergence of the LIW main path and our BOUM section, and by the uplift of the $29.17 \mathrm{~kg} \mathrm{~m}^{-3}$ isopycnal induced by the Strait of Sicily outflow toward the western MS. The main deep flow is channelized by the narrow trench there. The LIW core water from the LIW northern path has a high AOU value $(62 \mu \mathrm{M})$ because it flows under 
the northern areas of the eastern MS which are more productive. If we are correct, the consequence is that LIW flowing towards the Strait of Sicily was mainly fuelled by the northern path of LIW, and not by the interior of the Ionian basin eddy flow. The trajectories of recent floats in the Ionian basin (not shown) also confirm this. After the Strait of Sicily, due to the local mixing, $S_{\max }$ and $S\left(\mathrm{AOU}_{\mathrm{Max}}\right)$ evolved together closely in the western MS, as it is well known.

\subsubsection{N:P ratio of deep waters}

A $\Delta \mathrm{NO}_{3}: \Delta \mathrm{PO}_{4}$ ratio of 17.7 , close to the $\mathrm{Rr}$ of 16 , was found in the deep layers of the MS (Pujo-Pay et al., 2011). Such a ratio was assumed, on the scale of the world ocean, to be the result of the mineralization of fast-sinking particles consisting of fresh organic matter known to follow the Rr, with no depth specific mineralisation for each element (Anderson and Sarmiento, 1994). The $\mathrm{N}^{*}$ parameter represents the mean offset of the $\Delta \mathrm{NO}_{3}: \Delta \mathrm{PO}_{4}$ regression line. Positive $\mathrm{N}^{*}$ values were measured in deep waters below 200$500 \mathrm{~m}$ confirming the $\mathrm{P}$ deficiency of the Mediterranean waters, and the particular oligotrophy of these waters compared to other oligotrophic areas in the world ocean. It is important to note that we did not consider the positive constant of $0.87 \times 2.9 \mathrm{mmol} \mathrm{m}^{-3}$ (i.e. $2.5 \mu \mathrm{mol}^{-1}$ ) added by Grüber and Sarmiento (1997) in their first definition to bring the global mean of $\mathrm{N}^{*}$ to about zero. It would have brought our mean value towards a value of $+4.6 \mu \mathrm{moll}^{-1}$ while $\mathrm{N}^{*}$ is roughly constant between -1 to $-2 \mu \mathrm{mol} \mathrm{kg} \mathrm{kg}^{-1}$ in deep waters (below $2000 \mathrm{~m}$ ) throughout the Pacific (Deutsch et al., 2001) and never exceeds $+2 \mu \mathrm{mol} \mathrm{kg}^{-1}$ in the deep Atlantic (Sarmiento and Grüber, 2006). The unique low P vs. N environmental characteristic of the deep MS waters with regards to the whole deep ocean waters is a fact.

The most probable explanation for the constant deep $\mathrm{N}^{*}$ value observed for the whole deep Mediterranean waters is that mineralisation of organic matter in deep waters follows the Rr. The necessary conditions are firstly that the nonrefractory, deep exported, organic material has relative $\mathrm{N}$ and $\mathrm{P}$ concentrations close to the $\mathrm{Rr}$, and secondly that nitrification largely exceeds denitrification in the remineralisation of organic matter. An inefficient denitrification in the MS has already been suggested by Krom et al. (2004). In addition, low $\mathrm{N}_{2}$ fixation rates were recently measured in the whole MS (Ibello et al., 2010; Yogev et al., 2011; Bonnet et al., 2011). Diazotroph organisms, known to provide organic matter with high N:P ratio, should therefore probably not represent significant biomass and exported material, even if their presence in the MS is no longer questionable (Le-Moal et al., 2011). As diatoms and their predators are known to follow the $\mathrm{Rr}$ ratio more closely than smaller organisms, and because they may play an unexpected role even in the very oligotrophic waters of the MS (Crombet et al., 2011), their relative contributions to the carbon cycle and export need to be reconsidered in the MS. Little is known about the sporadic and probably "deep" diatom blooms in the MS, but the constant $\mathrm{N}^{*}$ value of the deep waters allows us to consider a similar, and probably not very different, biogeochemistry of the eastern and western MS from the rest of the ocean. The large changes in $\mathrm{N}^{*}$ are spatially localized to specific areas in the world ocean.

The constant deep $\mathrm{N}^{*}$ value of $2.11 \mu \mathrm{M}(\mathrm{sd}=0.25 \mu \mathrm{M})$ remains to be explained. It is an $\mathrm{N}$-excess, which was probably not transferred to the deep layer by fast-sinking particles, from the surface layers. It means that this $\mathrm{N}$-excess was preexisting in the surface water at the time and in the area of deep water formation, before their subduction. Or, it is due to the rapid transfer of atmospheric deposits with N:P largely higher than the $\mathrm{Rr}$ (Krom et al., 2010). The long-term origin of the $\mathrm{N}$-excess in the deep MS waters and its homogeneity in the western and eastern basins needs further confirmation.

\subsection{The eddies as giant mesocosms allowing to draw first-order budgets}

\subsubsection{Specific characteristics}

Eddy $\mathrm{C}$ observed above the Eratosthenes Seamount was, as already discussed, similar to the long-lived Cyprus eddy observed in the late 1980s (Brenner, 1993; Krom et al., 1992, 1993) located $150 \mathrm{~km}$ east of eddy C. We do not know of any specific study on an eddy like eddy B in the Ionian basin. Eddy $\mathrm{A}$ is similar to eddies studied in the Algerian basin of the western MS during ELISA cruises, but no deep biogeochemical and biological investigations were done at this time; ELISA eddies were observed as long-lived eddies (Millot and Taupier-Letage, 2005). The three main eddies studied during the BOUM cruise had different physical characteristics, probably because of their different area of formation (see Sect. 3), but all of them are marked by significant $\delta G$ and by strong biogeochemical anomalies (Fig. 7). Integrated $(20-850 \mathrm{~m})$ AOU anomalies were $<0$ and of -8000 to $-9500 \mu \mathrm{mol} \mathrm{m}{ }^{-2}$, which gives an averaged depth anomaly more negative than $-10 \mu \mathrm{mol} \mathrm{kg}{ }^{-1}$, which is strongly significant.

The variability was low in all physical and biogeochemical vertical profiles performed at each LD station (Fig. 10 and Fig. 11) unless a curve spatial drift of the mooring line followed longer than $15 \mathrm{~km}$ (visible by a zoom of the three panels on Fig. 3 bottom). This could be obtained only close to an eddy axis. As the mooring line was initially at a smaller distance from eddy axis than $3-5 \mathrm{~km}$, this relatively large drift was interpreted as a composite effect of the displacement of the eddy axis, and of the mooring line rotation around the axis. This is confirmed by the detailed study (not shown) of ADCP currents. We insist on this point because such eddy studies have rarely been undertaken so close to the eddy axis. Therefore, the properties of the full eddy cores were documented as discussed above, and biological processes could be studied without taking into account horizontal advection 
and modification of water parcels (eddies can be analysed as giant mesocosms). This was one of the objectives of the BOUM experiment (Moutin et al., 2012), and is also true for the surface layer protected by the vorticity barrier (see SM).

\subsubsection{N-budget}

The use of estimated eddy diffusion coefficients for the calculation of diffusive fluxes is considered to be a prime source of inaccuracy in N-budget calculations (Codispoti et al., 1989; Moutin and Raimbault, 2002). Real measurements using high-frequency temperature measurements were carried out for the first time during the BOUM cruise (Cuypers et al., 2012) in order to provide accurate Kz. The mean value measured $\left(0.86 \mathrm{~m}^{2} \mathrm{j}^{-1}\right)$ is in the large $0.1-2 \mathrm{~m}^{2} \mathrm{~d}^{-1}$ (i.e. $0.1-$ $\left.2.310^{-5} \mathrm{~m}^{2} \mathrm{~S}^{-1}\right)$ range previously estimated by Moutin and Raimbault (2002).

We found a new $\mathrm{N}$-input in the photic zone slightly higher than the $\mathrm{N}$-export, but in a state close to equilibrium where input equals loss, as was expected. The slight overestimation could probably be explained by an overestimation of atmospheric deposition which is spatially and temporarily highly variable. It is important to note that our estimations are below the daily $\mathrm{N}$-flux range between 79.2 and $213.4 \mu \mathrm{mol} \mathrm{m}{ }^{-2} \mathrm{~d}^{-1}$ that could be calculated from annual fluxes measured at the ADIOS sampling sites in the eastern MS and mainly associated with wet deposition (Markaki et al., 2010). No wet deposition was observed at the time of the cruise. Nevertheless, atmospheric deposition seems to represent a significant part of new N-input, particularly in the eastern eddy. This is in agreement with recent studies showing the importance of atmospheric deposition for the biogeochemistry of the MS (Krom et al., 2010 and references inside). Nevertheless, direct measurements of atmospheric deposition at sea remain unavailable which makes the relative importance of this input of new $\mathrm{N}$ for eddies still doubtful.

During the strongest stratified period of the BOUM cruise, export represents approximately $1 \%$ of GPP, which is therefore $99 \%$ fuelled by nutrients regenerated in the photic zone. These results are among the lowest obtained in the Mediterranean Sea and in the oligotrophic ocean in general (Moutin and Raimbault, 2002). Note that mineralisation of particulate organic matter between the deepest depth where NPP was measured (around $150 \mathrm{~m}$ ) and the first depth where traps were deployed $(230 \mathrm{~m})$ is not considered in our calculation. However, this is probably extremely low at the daily scale given the near identical values obtained in the traps at 230 and $460 \mathrm{~m}$ at $\mathrm{LD}$ station $\mathrm{C}$ for $\mathrm{N}$-export (Table 3 ).

\subsubsection{Towards a carbon budget}

We found a summer budget near equilibrium. A first level of interpretation suggests that anticyclonic eddies may bring nutrients up to the surface from deeper water in winter, allowing higher production and subsequently increasing the biological pump. Nevertheless, because of the deepening of the isohalines and the nitrate isopleths, the net input of nitrate in the photic zone is probably not very different from waters outside the eddies, and so the biological pump globally could not be changed. Note that this conclusion will largely depend on the interannual variability of the W-MLD.

The fact that AOU was low inside the eddies, together with the near-identical export measured at 230 and $460 \mathrm{~m}$, seems to indicate that eddy cores are areas where low mineralisation of particulate organic matter occurs. This can probably be related to the pycnostads observed inside the eddies in favour of a deeper settling of particles inside the eddies than outside. "In" and "out" AOU comparisons (Fig. 8 top) indicate lower mineralisation inside the eddies. Assuming a similar primary production inside and outside, the anticyclonic eddies might be more efficient for $\mathrm{CO}_{2}$ sequestration through sedimentation of fast-sinking particulate organic matter towards deeper layers. The difference in mineralisation (Fig. 8 top) should probably be attributed primarily to the age of water masses, which are predominantly younger inside the eddies cores than outside. A thorough budget should also focus on this subject.

The three eddies are enriched in dissolved organic carbon (DOC), (Fig. 7 this manuscript and Fig. 5 in Pujo Pay et al. 2011). Depth averaged $(20-500 \mathrm{~m})$ DOC anomalies are positive and of about $5 \mu \mathrm{M}$. Sequestration of $\mathrm{CO}_{2}$ by vertical export of accumulated DOC seems to be higher inside eddies. It is considered to be the main organic carbon transport from the surface to deeper layers in the MS (Copin-Montégut and Avril, 1993; Avril, 2002). In addition, this sequestration seems to be accentuated by anticyclonic eddies and probably occurs primarily when the eddy disappears and excess DOC definitely escapes via further winter ventilation. The life of anticyclonic eddies in the MS varies between several months to several years (Puillat et al., 2002; Taupier-Letage, 2008). The very rapid displacement of the PROVOR float (WMO 6900679) during winter 2009 seems to indicate that eddy C disappeared just after the observation of substantial vertical mixing. LIW formed in eddy C (Sect. 3.1) and found trapped in the core of eddy $B_{\text {deep }}$ which can be deemed very efficient in trapping accumulated DOC in the intermediate water circulation. Accumulation of DOC in the upper surface waters can be attributed to various causes. Low phosphate availability renders heterotrophic bacteria more limited by phosphate than by carbon, leading to DOC accumulation (Thingstad et al., 1997). The unusually high N:P ratio of the MS, which may favour the uncoupling between growth and carbon production, also leads to DOC accumulation (Mauriac et al., 2011). The relative importance of DOC transport in the biological pump is probably one of the main characteristics of LPLC areas, and it is likely reinforced inside anticyclonic eddies. 


\section{Conclusions}

The eastward-westward BOUM transect, covering essentially the southern part of the basins, enabled the physical and biogeochemical states of the MS to be observed during summer 2008. The main known water masses were found and interpreted using previous knowledge of the recent events of deep water formations occurring in the eastern (EMT in the 1990s) and western (2005 and 2006 in the northwestern) basins, which were still visible in the deep layer.

The results presented and the specific discussion about the intermediate layer in the MS allow to show that a Levantine type water recently formed in eddy $\mathrm{C}$, slightly warmer and saltier than LIW usually formed in the Rhodes gyre. The physical and biogeochemical characteristics of LIW could change during its progression towards the channel of Sicily, by undergoing several winter ventilations. The deepening of LIW core in the eastern MS, from its area of formation and towards the east, is marked and characterized by a step-bystep decrease in $S_{\max }$ and simultaneaous increases in density at $S_{\max }$ and $\mathrm{AOU}\left(S_{\max }\right)$. The following scenario was proposed: When LIW flows along the northern coasts, some eddies with LIW formed in winter and ventilated at their core. Then, the fraction of LIW kept in eddies is transported by the drifting of their cores towards the south (where they have been observed), and ultimately LIW is mixed with the surrounding water when the eddies disappear. This scenario nevertheless needs to be validated when more data become available.

The previously known, main longitudinal trends were confirmed and further refined. They are, from the west to the east, an increase in $S, T$, AOU, DOC in the $0-850 \mathrm{~m}$ layer, a deepening of $\mathrm{D}_{\mathrm{NO}_{3}}$, EZD and depth of layer of nil AOU confirming the oligotrophic gradient. Large differences in nutrient concentrations were found in the deep layer, but with a constant and positive homogeneous $\mathrm{N}^{*}$ in the eastern and western basins. These general trends were locally disturbed by five eddies, three of them studied in detail. Compared with general trends, anticyclonic eddies display strong anomalies in $S, \theta, \sigma, \mathrm{AOU}, \mathrm{DOC}$ and DIC for layers of more than several hundred meters. A pycnostad and a large layer with constant nutrient and AOU were found close to each eddy axis. We showed that this is the result of a recent ventilation in winter 2008 associated with a deep W-MLD followed by a shoaling of the mixed layer induced by the stratification of the surface layers during spring. When stratification occurs, the bottom of this ventilated layer, which is deeper than the EZD, escapes from the atmospheric influence, and an upper nutricline formed near the EZD. The main nutricline remains at the bottom of the eddy core.

Primary production and export were found to be extremely low inside eddies during summer, with less than $1 \%$ of new production supplied by diffusive $\mathrm{N}$-fluxes from the upper nitracline, which means that eddy core properties are not modified. Relatively high DOC concentrations were measured in- side eddy core, and interpreted as the result of the winter mixing of the dissolved organic matter inventory accumulated before winter. The high DOC values found are indicative of a low DOC remineralisation. Finally, eddies, having a strong and deep impact on the vertical distribution of biogeochemical properties, tend towards ultraoligotrophic ecosystems during summer, even in the western MS. They also appear as systems able to influence the biological carbon pump, particularly the ratio between dissolved vs. particulate carbon export.

As the BOUM experiment was performed during the beginning of summer, we cannot rule on the real role of eddies during the beginning of the stratification period. Our results nevertheless show that the possible high biomass production during that period will crucially depend on a possible refuelling of the photic layer by nutrients from the main nutricline in winter.

\section{Supplementary material related to this article is available online at: http://www.biogeosciences.net/9/ 3827/2012/bg-9-3827-2012-supplement..pdf.}

Acknowledgements. This is a contribution of the BOUM (Biogeochemistry from the Oligotrophic to the Ultraoligotrophic Mediterranean) experiment (http://mio.pytheas.univ-amu.fr/BOUM/) of the French national LEFE-CYBER program, the European IP SESAME and the international IMBER project. The BOUM experiment was coordinated by the Institut des Sciences de l'Univers (INSU) and managed by the Centre National de la Recherche Scientifique (CNRS). The authors thank the crew of the R/V L'Atalante for their outstanding shipboard operations. C. Marec and L. Prieur are warmly thanked for their efficient help in CTD rosette management and data processing as is Marie Paule Torre for the LEFE CYBER database management. Nathalie Leblond is acknowledged for her work on sediment trap. Martine Aperio and Catherine Perrot are acknowledged for the administrative work.

Edited by: C. Jeanthon

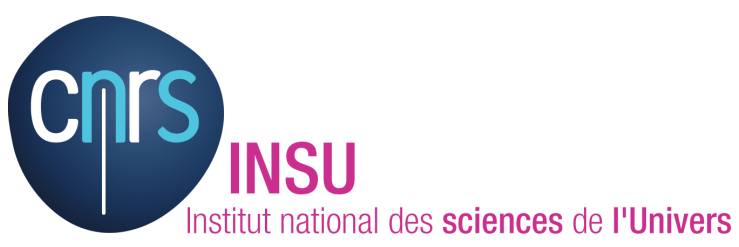

The publication of this article is financed by CNRS-INSU. 


\section{References}

Anderson, L. A. and Sarmiento, J. L.: Redfield ratios of remineralization determined by nutrients data analysis, Global Biogeochem. Cy., 8, 65-80, 1994.

Avril, B.: DOC Dynamics in the northwestern Mediterranean Sea (DYFAMED site), Deep-Sea Res. Pt. II, 49, 2163-2182, 2002.

Behrenfeld, M. J.: Abandoning Sverdrup's Critical Depth Hypothesis on phytoplankton blooms, Ecology, 91, 977-989, 2010.

Benitez-Nelson, C. R. and McGuillicuddy D. J.: Mesoscale Physical-Biological-Biogeochemical Linkages in the Open Ocean: An Introduction to the results of the E-Flux and EDDIES Programs (Preface), Deep-Sea Res. Pt. II, 55, 1133-1138, 2008.

Béthoux, J. P. and Copin-Montégut, G.: Biological fixation of atmospheric nitrogen in the Mediterranean Sea, Limnol. Oceanogr., 31, 1353-1358, 1986.

Bonin, D. J., Bonin, M. C., and Berman, T.: Mise en évidence expérimentale des facteurs nutritifs limitants de la production du micro-nanoplancton et de l'ultraplancton dans une eau côtière de la Méditerranée orientale (Haïfa, Israël), Aquat. Sci., 51, 132$148,1989$.

Bonnet, S., Grosso, O., and Moutin, T.: Planktonic dinitrogen fixation along a longitudinal gradient across the Mediterranean Sea during the stratified period (BOUM cruise), Biogeosciences, 8, 2257-2267, doi:10.5194/bg-8-2257-2011, 2011.

Brenner, S.: Long-term evolution and dynamics of a persistent warm core eddy in the eastern Mediterranean Sea. Deep-Sea Res. Pt. II 40, 1193-1206, 1993.

Chapman, R. and Nof, D.: The sinking of Warm-Core rings, J. Phys. Oceanog., 18, 565-583, 1988.

Chiswell, S. M.: Annual cycles and spring blooms in phytoplankton: don't abandon Sverdup completely, Mar. Ecol. Prog. Ser., 443, 39-50, 2011.

Christaki, U., Van Wambeke, F., Lefevre, D., Lagaria, A., Prieur, L., Pujo-Pay, M., Grattepanche, J.-D., Colombet, J., Psarra, S., Dolan, J. R., Sime-Ngando, T., Conan, P., Weinbauer, M. G., and Moutin, T.: Microbial food webs and metabolic state across oligotrophic waters of the Mediterranean Sea during summer, Biogeosciences, 8, 1839-1852, doi:10.5194/bg-8-1839-2011, 2011.

CIESM: Dynamics of Mediterranean deep waters. No 38 in CIESM Workshop Monographs, edited by: Briand, F., 132 p., Monaco, available at: http://www.ciesm.org/online/monographs/ index.htm 2009.

Codispoti, L. A.: Phosphorus vs. nitrogen limitation of new and export production, in Productivity of the Ocean: Present and Past, edited by: Berger, W. H., Smetacek, V. S., and Wefer, G., 377394, John Wiley \& Sons, New York, 1989.

Copin-Montégut, G., and Avril, B.: Vertical distribution and temporal variation of dissolved organic carbon in the North-Western Mediterranean Sea, Deep-Sea Res., 40, 1963-1972, 1993.

Coste, B., Minas, H. J., and Bonin, M. C.: Proprités hydrologiques et chimiques des eaux du bassin Occidental de la Mediterranee, Campagne MEDIPROD 4. Publ. CNEXO, Ser. Result, Campagnes Mer No. 26, 106 p, 1984.

Crispi, G., Mosetti, R., Solidoro, C., and Crise, A.: Nutrient cycling in the Mediterranean Basin: the role of biological pump in the trophic regime, Ecol. Modell., 138, 101-114, 2001.

Crombet, Y., Leblanc, K., Quéguiner, B., Moutin, T., Rimmelin, P., Ras, J., Claustre, H., Leblond, N., Oriol, L., and Pujo-Pay, M.: Deep silicon maxima in the stratified oligotrophic Mediter- ranean Sea, Biogeosciences, 8, 459-475, doi:10.5194/bg-8-4592011, 2011.

Cuypers, Y., Bouruet-Aubertot, P., Marec, C., and Fuda, J.-L.: Characterization of turbulence from a fine-scale parameterization and microstructure measurements in the Mediterranean Sea during the BOUM experiment, Biogeosciences, 9, 3131-3149, doi:10.5194/bg-9-3131-2012, 2012.

Deutsch, C., Gruber, N., Key, R. M., Sarmiento J. L., and Ganachaud, A.: Denitrification and $\mathrm{N}_{2}$ fixation in the Pacific Ocean. Global Biogeochem. Cycles, 15, 483-506, 2001.

D'Ortenzio, F. and Ribera d'Alcalà, M.: On the trophic regimes of the Mediterranean Sea: a satellite analysis, Biogeosciences, 6, 139-148, doi:10.5194/bg-6-139-2009, 2009.

D'Ortenzio, F. and Prieur, L.: The upper mixed layer, in: Life in the Mediterranean Sea: A look at habitat changes, edited by: Noga Stambler, Nova Science Publisher, Chapter 5, 127-156, ISBN 978-1-61209-644-5, 2012.

D’Ovidio, F., De Monte, S., Alvain, S., Dandonneau, Y., and Lévy, M.: Fluid dynamical niches of phytoplankton types, Proc. Natl. Acad. Sci. USA., 107, 18366-18370, doi:10.1073/pnas.1004620107, 2010.

Fusco, G., Manzella, G. M. R., Cruzado, A., Gačić, M., Gasparini, G. P., Kovačvić, V., Millot, C., Tziavos, C., Velasquez, Z. R., Walne, A., Zervakis, V., and Zodiatis, G.: Variability of mesoscale features in the Mediterranean Sea from XBT data analysis, Ann. Geophys., 21, 21-32, doi:10.5194/angeo-21-212003, 2003.

Gruber, N. and Sarmiento, J. L.: Global patterns of marine nitrogen fixation and denitrification, Global Biogeochem. Cy., 11, 235266, 1997.

Ibello, V., Cantoni, C., Cozzi, S., and Civitarese, G.: First basin-wide experimental results on $\mathrm{N} 2$ fixation in the open Mediterranean Sea, Geophys. Res. Lett., 37, L03608, doi:10.1029/2009GL041635, 2010.

Jenkins, W.J., McGuillicuddy, D.J., Lott, D.E.: The Distributions of, and Relationship Between ${ }^{3} \mathrm{He}$ and Nitrate in Eddies, Deep-Sea Res. II, 55, 1389-1397, 2008.

Karl, D. M., Michaels, A., Bergman, B., Capone, D. G., Carpenter, R. C., Letelier, R., Lipschultz, F., Paerl, H. W., Sigman, D. M., and Stal, L.: Dinitrogen fixation in the world's oceans, Biochemistry, 57-58, 47-98, 2002.

Kerhervé, P., Minagawa, M., Heussner, S., and Monaco, A.: Stable isotopes $\left({ }^{13} \mathrm{C} /{ }^{12} \mathrm{C}\right.$ and $\left.{ }^{15} \mathrm{~N} /{ }^{14} \mathrm{~N}\right)$ in settling organic matter of the northwestern Mediterranean Sea: biogeochemical implications, Ocean. Ac., 24 supplement: S77-S85, 2001.

Krom, M. D., Brenner, S., Kress, N., Neori, A., and Gordon, L. I.: Nutrient distributions during an annual cycle across a warmcore eddy from the E. Mediterranean Sea, Deep-Sea Res Pt. I, 40, 805-825, 1993.

Krom, M. D., Brenner, S., Kress, N., Neori, A., and Gordon, L. I.: Nutrient dynamics and new production in a warm-core eddy from the E. Mediterranean, Deep-Sea Res., 39, 467-480, 1992.

Krom, M. D., Kress, N., and Brenner, S.: Phosphorus limitation of primary productivity in the eastern Mediterranean Sea, Limnol. Oceanogr., 36, 424-432, 1991.

Krom, M. D., Herut, B., and Mantoura, R. F. C.: Nutrient budget for the Eastern Mediterranean: implications for P limitation, Limnol. and Oceanogr., 49, 1582-1592, 2004. 
Krom, M.D., Emeis, K. C., Van Cappellen, P.: Why is the Western Meditteranean phosphorus limited? Prog. Oceanogr., 85, 236$244,2010$.

Lascaratos, A., Roether, W., Nittis, K., and Klein, B.: Recent changes in the Eastern Mediterranean Deep Waters: a review, Progr. Oceanogr., 44, 5-36, 1999.

Le Moal, M., Collin, H., and Biegala, I. C.: Intriguing diversity among diazotrophic picoplankton along a Mediterranean transect: a dominance of rhizobia, Biogeosciences, 8, 827-840, doi:10.5194/bg-8-827-2011, 2011.

Ledwell, J. R., McGuillicuddy, D. J., and Anderson, L. A.: Nutrient Flux into an Intense Deep Chlorophyll Layer in a Mode-water Eddy. Deep Sea Res. Pt. II, 55, 1139-1160, 2008.

Lévy, M.: The modulation of biological production by oceanic mesoscal turbulence, Lect. Notes Phys., 744, 219-261, doi:10.1007/978-3-540-75215-8_9, Transport in Geophysical flow: Ten years after, edited by: Weiss, J. B. and Provenzale, A., Springler, 2008.

Malanotte-Rizzoli, P., Manca, B.B., Ribera d'Alcalà, M., Theocharis, A., Brenner S., Budillon G., and Ozsoy E.: The Eastern Mediterranean in the ' 80 s and in the '90s: the big transition in the intermediate and deep circulations, Dynam. Atmos. Oceans, 29, 365-395, 1999.

Markaki, Z., Loye-Pilot, M. D., Violaki, K., and Mihalopoulos, N.: Variability of atmospheric deposition of dissolved nitrogen and phosphorus in the Mediterranean and possible link to the anomalous seawater N/P ratio, Mar. Chem., 120, 187-194, 2010.

Mauriac, R., Moutin, T., and Baklouti, M.: Accumulation of DOC in Low Phosphate Low Chlorophyll (LPLC) area: is it related to higher production under high N:P ratio?, Biogeosciences, 8, 933-950, doi:10.5194/bg-8-933-2011, 2011.

Mc Gill, D. A.: A preliminary study of the oxygen and phosphate distribution in the Mediterranean Sea, Deep Sea Res., 8, 259269, 1961.

Mc Gill, D. A.: The relative supplies of phosphate, nitrate and silicate in the Mediterranean Sea, Comm. Int. Mer Medit., 18, 737744, 1965.

McGuillicuddy D. J. Jr., Johnson R., Siegel D. A., Michaels A . F., Bates N. R., and Knap A. H.: Mesoscale variations of biogeochemical properties in the Sargasso Sea, J.Geophys.Res., 104, 13381-13394, 1999.

McGuillicuddy, D. J., Anderson, L. A., Bates, N. R., Bibby, T., Buesseler, K., Carlson, C., Davis, C. S., Ewart, C., Falkowski, P. G., Goldthwait, S. A., Hansel, D. A., Jenkins, W. J., Johnson, R., Kosnyrev, V. K., Ledwell, J. R., Li, Q. P., Siegel, D. A., and Steinberg, D. K.: Eddy-wind interactions stimulate extraordinary mid-ocean plankton blooms, Science 316, 1021-1026, 2007.

Menna, M. and Poulain, P. M.: Mediterranean intermediate circulation estimated from Argo data in 2003-2010, Ocean Sci., 6, 331-343, doi:10.5194/os-6-331-2010, 2010.

Millot, C. and Taupier-Letage I.: Circulation in the Mediterranean Sea, Hdb. Env. Chem., Vol. 5(Part K), 29-66, doi:10.1007/b107143, 2005.

Morel, A. and Maritorena, S.: Bio-optical properties of oceanic waters: A reappraisal, J. Geophys. Res., 106, 7763-7780, 2001.

Moutin, T. and Raimbault, P.: Primary production, carbon export and nutrients availability in western and eastern Mediterranean Sea in early summer 1996 (MINOS cruise), J. Mar. Syst., 33/34, 273-288, 2002.
Moutin, T., Thingstad, T. F., Van Wambeke, F., Marie, D., Slawyk, G., Raimbault, P., and Claustre, H.: Does competition for nano-molar phosphate supply explain the predominance of the cyanobacterium Synechococcus? Limnol. Oceanogr., 47, 15621567, 2002.

Moutin, T., Van Wambeke, F., and Prieur, L.: Introduction to the Biogeochemistry from the Oligotrophic to the Ultraoligotrophic Mediterranean (BOUM) experiment, Biogeosciences, 9, 38173825, doi:10.5194/bg-9-3817-2012, 2012.

Moutin, T., Raimbault, P., and Poggiale, J. C.: Production primaire dans les eaux de surface de la Méditerranée occidentale: Calcul de la production journalière, C. R. Acad. Sci. Paris, Sciences de la vie, 322, 651-659, 1999.

Pan, G., Krom, M. D., and Herut, B.: Adsorption-desorption of phosphate on airborne dust and riverborne particulates in East Mediterranean seawater, Environ. Sci. Technol., 36, 3519-3524, doi:10.1021/es020516d, 2002.

Pantoja, S., Repeta, D. J., Sachs, J. P., and Sigman, D. M.: Stable isotope constraints on the nitrogen cycle of the Mediterranean Sea water column, Deep Sea Res. Pt. I, 49, 1609-1621, 2002.

Pingree R. D. and Le Cann, B.: Anticyclonic Eddy X91 in the Southern Bay of Biscay, May 1991 to February 1992., J. Geophys. Res., 97, 14353-14367, 1992.

Pingree R. D. and Le Cann, B.: A Shallow Meddy (A Smeddy) From the Secondary Mediterranean Salinity Maximum, J. Geophys. Res., 98, 20169-20185, 1993.

Puillat, I., Taupier-Letage, I., and Millot, C.: Algerian Eddies lifetime can near 3 years, J. Mar. Syst., 31, 245-259, 2002.

Pujo-Pay, M., Conan, P., Oriol, L., Cornet-Barthaux, V., Falco, C., Ghiglione, J.-F., Goyet, C., Moutin, T., and Prieur, L.: Integrated survey of elemental stoichiometry $(\mathrm{C}, \mathrm{N}, \mathrm{P})$ from the western to eastern Mediterranean Sea, Biogeosciences, 8, 883899, doi:10.5194/bg-8-883-2011, 2011.

Raimbault, P. and Coste, B.: Very high values of nitrate:phosphate ratio $(>30)$ in the subsurface layers of the western Mediterranean Sea, Rapp. Comm. Int. Mer. Médit., 32, C-18, 1990.

Redfield, A. C., Ketchum, B. H., and Richards, F. A.: The influence of organisms on the composition of sea water, in: The Sea, ideas and observations on progress in the study of the sea, edited by: Hill, M. M., Vol. 2, J. Wiley and Sons, New-York, 26-77, 1963.

Ridame, C., Moutin, T., and Guieu, C.: Does phosphate adsorption onto Saharan dust explain the unusual N/P ratio in the Mediterranean Sea? Ocean. Ac., 629-634, 2003.

Robinson A. R., Golnaraghi M., Leslie W. G., Artegiani A., Hecht A., Lazzon E., Michelato A., Sansone E., Theocharls A., and Ünlüata, Ü.: The eastern Mediterranean general circulation: features, structure and variability, Dynam. Atmos. Ocean., 15, 215240, 1991.

Roether, W., Klein, B., Manca, B.B., Theocharis, A., and Kioroglou S.: Transient Eastern Mediterranean deep waters in response to the massive dense-water output of the Aegean Sea in the 1990s. Progr. Oceanogr., 74, 540-571, doi:10.1016/j.pocean.2007.03.001, 2007.

Rubino, A. and Hainbucher, D.: A large abrupt change in the abyssal water masses of the Eastern Mediterranean, Geophys. Res. Lett., 34, L23607, doi:10.1029/2007GL031737, 2007.

Sachs J. P. and Repeta, D. J.: Oligotrophy and nitrogen fixation during eastern Mediterranean sapropel events, Science, 286, 24852488, 1999. 
Sarmiento, J. L., Herbert, T., and Toggweiler, J. R.: Mediterranean nutrient balance and episodes of anoxia, Global Biogeochem. Cy., 2, 427-444, doi:10.1029/GB002i004p00427, 1988.

Sarmiento, J. L. and Gruber, N.: Ocean Biogeochemical Dynamics, Princeton University Press, Princeton, 503 pp, 2006.

Schroeder K., Ribotti, A., Borghini, M., Sorgente, R., Perilli, A., and Gasparini, G. P.: An extensive western Mediterranean deep water renewal between 2004 and 2006, Geophys. Res. Lett., 35, L18605, doi:10.1029/2008GL035146, 2008.

Stratford, K., Williams, R. G., and Myers, P. G.: Impact of the circulation on sapropel formation in the eastern Mediterranean, Global Biogeochem. Cy., 14, 683-695, 2000.

Sweeney, E. N., McGuillicuddy, D. J., and Buesseler, K. O.: Biogeochemical impacts due to mesoscale eddy activity in the Sargasso Sea as measured at the Bermuda Atlantic Time-series Study (BATS), Deep-Sea Res. Pt. II, 50, 3017-3039, 2003.

Taupier-Letage, I.: On the use of thermal images for circulation studies: Application to the eastern Mediterranean basin, in: Remote Sensing of the European Sea, edited by: Barale, V. and Gade, M., Springer Verlag, 153-164, 2008.
Thingstad, T. F., Hagström, A., and Rassoulzadegan, F.: Accumulation of degradable DOC in surface waters: Is it caused by a malfunctioning microbial loop? Limnol. Oceanogr., 42, 398-404, 1997.

Wu, P. and Haines, K.: Modeling the dispersal of Levantine Intermediate Water and its role in Mediterranean deep water formation, J. Geophys. Res., 101, 6591-6607, 1996.

Wüst, G.: On the vertical circulation of the Mediterranean Sea, J. Geophys. Res., 66, 3261-3271, 1961.

Yogev, T., Rahav, E., Bar-Zeev, E., Man-Aharonovich, D., Stambler, N., Kress, N., Beja, O., Mulholland, M. R., Herut, B., and Berman-Frank, I.: Is dinitrogen fixation significant in the Levantine Basin, East Mediterranean Sea?, Environ. Microbiol., article first published online: 18 January 2011, doi:10.1111/j.14622920.2010.02402, 2011. 